\title{
Rosmarinic Acid and Ulvan from Terrestrial and Marine Sources in Anti-Microbial Bionanosystems and Biomaterials
}

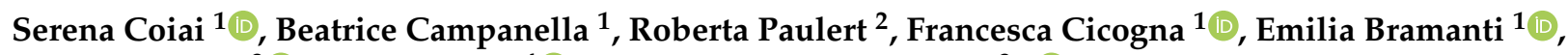 \\ Andrea Lazzeri ${ }^{3}\left(\mathbb{D}\right.$, Laura Pistelli ${ }^{4}$ (D) and Maria-Beatrice Coltelli ${ }^{3, *}$ (D) \\ 1 Consiglio Nazionale delle Ricerche, Istituto di Chimica dei Composti Organo Metallici (CNR-ICCOM), \\ SS Pisa, Via Moruzzi 1, 56124 Pisa, Italy; serena.coiai@pi.iccom.cnr.it (S.C.); \\ beatrice.campanella@pi.iccom.cnr.it (B.C.); francesca.cicogna@pi.iccom.cnr.it (F.C.); \\ emilia.bramanti@pi.iccom.cnr.it (E.B.) \\ 2 Department of Agronomic Sciences, Federal University of Paraná, Palotina 950-000, Brazil; roberta@ufpr.br \\ 3 Department of Civil and Industrial Engineering, University of Pisa, Via Diotisalvi 2, 56122 Pisa, Italy; \\ andrea.lazzeri@unipi.it \\ 4 Department of Agriculture, Food and Environment, University of Pisa, Via del Borghetto 80, 56124 Pisa, Italy; \\ laura.pistelli@unipi.it \\ * Correspondence: maria.beatrice.coltelli@unipi.it
}

check for updates

Citation: Coiai, S.; Campanella, B.; Paulert, R.; Cicogna, F.; Bramanti, E.; Lazzeri, A.; Pistelli, L.; Coltelli, M.-B. Rosmarinic Acid and Ulvan from Terrestrial and Marine Sources in Anti-Microbial Bionanosystems and Biomaterials. Appl. Sci. 2021, 11, 9249. https://doi.org/10.3390/app11199249

Academic Editor: Alejandro

Rodriguez Pascual

Received: 8 September 2021

Accepted: 29 September 2021

Published: 5 October 2021

Publisher's Note: MDPI stays neutral with regard to jurisdictional claims in published maps and institutional affiliations.

Copyright: (c) 2021 by the authors. Licensee MDPI, Basel, Switzerland. This article is an open access article distributed under the terms and conditions of the Creative Commons Attribution (CC BY) license (https:// creativecommons.org/licenses/by/ $4.0 /)$.

\begin{abstract}
In order to increase their sustainability, antimicrobial renewable molecules are fundamental additions to consumer goods. Rosmarinic acid is extracted from several terrestrial plants and represents an effective anti-microbial agent. Ulvan, extracted from algae, is an anti-microbial polysaccharide. The present review is dedicated to discussing the sources and the extraction methodologies for obtaining rosmarinic acid and ulvan. Moreover, the preparation of bioanosystems, integrating the two molecules with organic or inorganic substrates, are reviewed as methodologies to increase their effectiveness and stability. Finally, the possibility of preparing functional biomaterials and anti-microbial final products is discussed, considering scientific literature. The performed analysis indicated that the production of both molecules is not yet performed with mature industrial technologies. Nevertheless, both molecules could potentially be used in the packaging, biomedical, pharmaceutical, cosmetic, sanitary and personal care sectors, despite some research being required for developing functional materials with specific properties to pave the way for many more applications.
\end{abstract}

Keywords: rosmarinic acid; ulvan; anti-microbial; anti-oxidant; sulfated polysaccharide; biomaterials; bionanosystems; nanomaterials; bionanotechnology; biomass extraction; biobased; renewable; sustainability; marine sources; aromatic plants; phytochemicals

\section{Introduction}

The necessity of using renewable sources for producing consumer goods is increasing and more and more carbon neutral products are becoming available on the market [1], thus avoiding unbalanced Green House Gases (GHG) emissions, generally associated at the end-of-life management of products (for instance incineration for fossil plastics), that are considered responsible for global warming [2].

Moreover, several renewable materials are biodegradable, and this can offer the additional opportunity of organic recycling by composting or anaerobic digestion for the end-of-life of such products [3]. This can be particularly advantageous in cases where products with a short life (thus generating relevant quantities of waste) are considered. Packaging, personal care, cosmetic and sanitary products are examples of widely diffused items that could be gradually replaced with renewable and biodegradable materials.

In addition, many renewable materials also show a high biocompatibility, that could facilitate their use in a wide range of applications associated with contact with body and skin [4]. Biopolymers, in particular polysaccharides such as starch [5], cellulose [6], 
chitin/chitosan [7] and pullulan [8,9], are widely investigated because of their high biocompatibility with human cells. Anti-microbial properties are also highly interesting for such consumer goods [10]. Many molecules and biomaterials from terrestrial or marine environments can be considered to formulate or modify these short-life products, as extensively explained by Massironi et al. in their review, specifically dedicated to polysaccharides [11]. Alves et al. [12] recently reviewed the numerous natural molecules from the marine environment showing anti-microbial properties that could be potentially used in cosmeceutical and nutraceutical applications because of their skin depigmentation, UV filters, anti-inflammatory, anti-wrinkle, antiaging, skin hydrating, antiacne, as well as antioxidant and cytoprotective properties. The authors evidenced that plant-derived molecules have some limitations because plants generally grow slowly, and their chemical composition varies from region to region, and from season to season. On the other hand, marine flora and fauna can be grown rapidly in large quantities and are made cost-effective by modern aquaculture techniques. In any case, molecules extracted from several terrestrial plants can be attractive, as evidenced by Faccio [13], because they are already widely available and can be found in different plants. An important advantage is that these molecules can often be obtained by agricultural discards or by-products [14]. As reviewed by Casanova and Santos [15], the proper encapsulation of such small molecules can be useful to better modulate their properties and for an easier integration of the functional molecules in the final product.

Supramolecular chemistry, focused on interaction forces between macromolecules, can be considered the interconnecting element between biobased renewable resources and new materials. In fact, if it is applied to biopolymers [16] or biomolecules, it allows specific interactions with other biopolymers, biomolecules or materials to be harnessed for producing new engineered biobased materials. On the other hand, nanotechnology approaches are also pivotal. In fact, nanotechnology deals with the production and use of materials and systems by controlling matter structural features on the nanometre scale, and it is considered the key technology of the twenty-first century. The ability to exploit the structures, function, processes, complexes and nanosystems of biological molecules to produce novel functional nanostructured biobased materials, highlights the rapidly growing field of bio-nanotechnology, which is a combination between nanotechnology and biotechnology [17]. In attempt to harness the functional potential of bioactive molecules extracted from a biomass, interaction at nanometric levels with specific nanoscaled materials should be promoted. This strategy could allow the intermolecular forces typical of functional biopolymers and lead to agglomeration [16], thus limiting their functional role. In addition, their combination with other nanostructured materials can result in the preparation of stable bio-nanosystems [17] that can improve the solubility and bioavailability of these substances, protect against environmental conditions, and enable their controlled release and target delivery.

In the present review, two different emerging anti-microbial biobased molecules are considered: rosmarinic acid, a molecule extractable from several plants, and ulvan, a biopolymer extractable from algae. The former is available from terrestrial, while the latter is from a marine biomass, hence they grant the possibility of using different abundant biomasses as possible sources. In addition, they were selected because they were recently found quite promising for producing nanostructured biomaterials with anti-microbial properties $[11,18,19]$.

Hence, to take stock of these molecules' potential, the present review gathers and discusses sources, extraction methods, realization of bio-nanosystems through several techniques, application of bio-nanosystems to obtain functional materials and possible final applications of these two active biomolecules following the general scheme of Figure 1. 


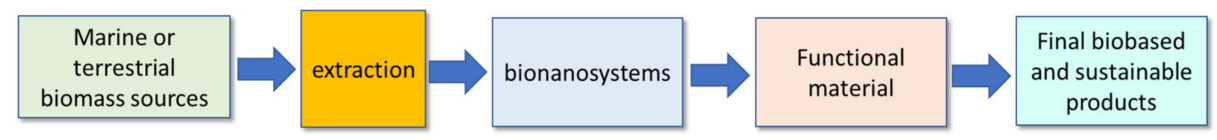

Figure 1. Scheme followed by the present review to discuss rosmarinic acid and ulvan potentialities in bionanosystems and final biobased products.

The aim of the review is, thus, to provide information about possible sources, extraction methodologies, and potential industrial chains for supporting new studies and further applications of promising high performance and sustainable biomaterials.

\section{Molecules, Properties, and Sources}

\subsection{Rosmarinic Acid}

The plant kingdom is the source of various phytochemicals that are used in a wide range of applications, from food preservatives to pharmaceutical and cosmetic industries [20]. A broad class of phytochemicals are antioxidants defined as compounds that inhibit or delay the oxidation of a target molecule [21]. Rosmarinic acid (RA) is a typical active antioxidant constituent and in the last 25 years, the RA attracted a large amount of research due to its presence in many spices and its use in food preservation.

RA is extensively distributed in the plant kingdom (26 families); it accumulates in many officinal plants, belonging to the Lamiaceae family (and their subfamily Nepeotoidae) and Boraginaceae, but it is also found in others such as Blechnaceae, Bryophytes (hornworts), and other species of dico and monotyledonous plants, part of the sea grass family Zosteraceae [22,23].

RA is stored in the vacuoles of plant cells; the chemical structure is an ester of caffeic acid and 3,4-hydroxyphenillactic acid and is one of the most frequently occurring caffeic acid ester in plants besides chlorogenic acid (Figure 2).<smiles>O=C(/C=C/c1ccc(O)c(O)c1)OC(Cc1ccc(O)c(O)c1)C(=O)O</smiles>

Figure 2. Rosmarinic acid formula.

Its name originated from the plant Rosmarinus officinalis L., from which RA was initially isolated [24]. The biosynthetic pathway has been first elucidated in Coleus blumei cell cultures [25] and the eight enzymes involved in the chemical pathway were deeply described in several Lamiaceae species.

RA biosynthesis follows two pathways: a phenylpropanoid branch, that drives to the caffeic acid moiety, and a tyrosine-derived branch that leads to the dihydroxyphenyllactic acid (DHPL) [26] (Figure 3).

In the phenylpropanoid pathway, L-phenylalanine is transformed to 4-coumaroylCoA by coupling the reactions catalyzed by phenylalanine ammonia lyase (PAL), cinnamic acid 4-hydroxylase $(\mathrm{C} 4 \mathrm{H})$, and 4-coumarate CoA ligase (4CL). For the tyrosine-derived moiety, the first step is the transamination of L-tyrosine by 2-oxoglutarate as a second substrate to form 4-hydroxyphenylpyruvate by tyrosine aminotransferase (TAT). Then, 4-hydroxyphenylpyruvate is transformed by hydroxyphenylpyruvate reductase (HPPR) to 4-hydroxyphenyllactate [27]; this product is then coupled with 4-coumaroyl CoA to form an intermediate by the enzyme rosmarinic acid synthase (RAS), whereby the aromatic 3-and $3^{\prime}$-hydroxyl positions are hydroxylated via cytochrome P450 to form the RA molecule [20]. 


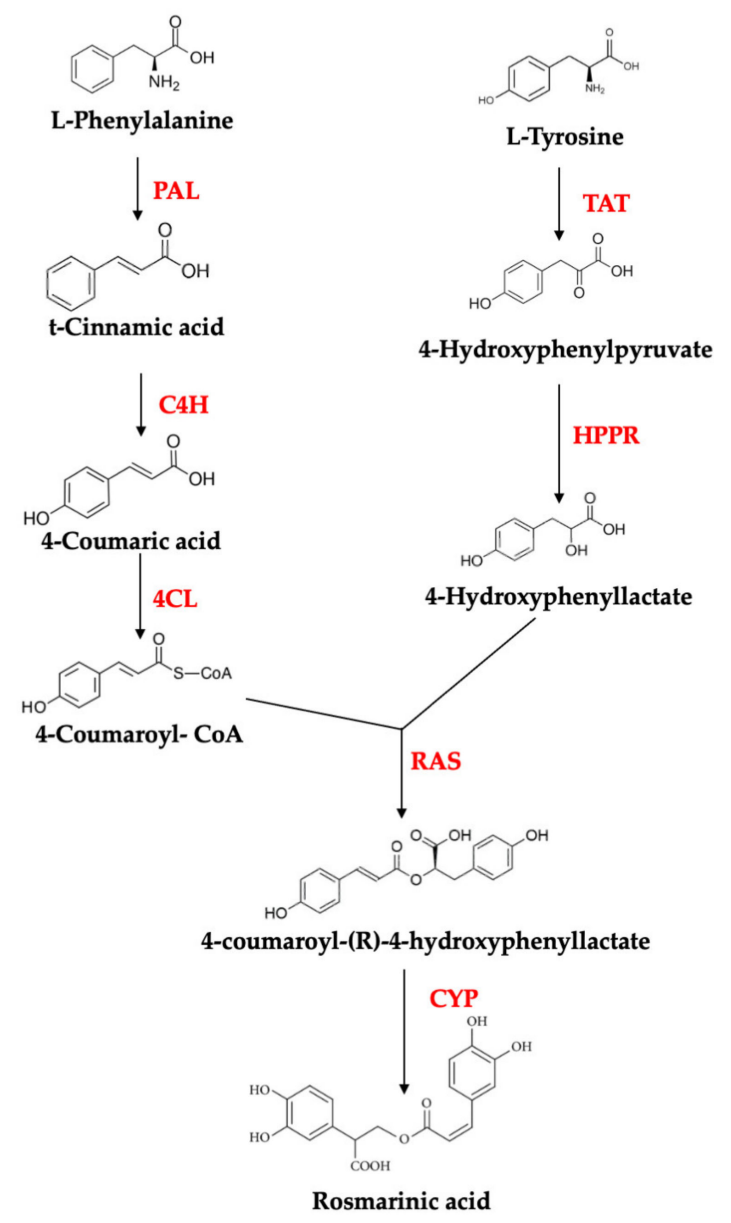

Figure 3. Biosynthetic pathway of rosmarinic acid.

RA is constitutively accumulated in the aerial parts of rosemary, sage, thyme, spearmint, lemon balm and lavender with different yield according to the vegetative or reproductive phase (reaching up to $11 \mathrm{mg} \mathrm{g}^{-1}$ of dry weight, [28]). However, plant cell cultures are an alternative and efficient source to produce this biologically important metabolite; the concentration of RA is thus enhanced and can reach up to $36 \%$ of dry weight (S. officinalis, [29]), much higher than in the plant itself. Other good sources of RA are hairy root cultures, e.g., from Ocimum basilicum (14.1\% DW; [30]).

RA is noted for its high antioxidant capacity, principally due to the high redox potential of its four phenolic hydrogens that support the ability to modulate free radical scavenging activity. A complementary support is given by the two catechol moieties that provide the suitable polarity for RA to penetrate the lipid bilayers and protect them against oxidation [31].

However, the biological activities of plant extracts containing RA have received considerable attention, and scientific reports have explored the various properties.

As antioxidant it is used in several applications within the food industry as a result of its role in scavenging free radicals and ability to chelate pro-oxidant ions, and thus prevent lipid peroxidation [32].

In the plant, RA is associated with defence against pathogens and herbivores, due to its tannin-like properties, and as a UV-protectants, due to its structure containing caffeic acid ester [23].

Numerous pharmacological and biological activities of RA have been described, ranging in complexity from in vitro to clinical studies, to humans and animals, showing anti-inflammatory, antimicrobial, cytotoxic, antimetastatic, antiangiogenic, neuroprotective, immunomodulatory, melanogenic effects $[4,23,31-34]$. 
More recently, RA has been positively involved in reducing the damage produced by UVB in human keratinocytes [31]. Moreover, important novel effects for RA regarding cognitive performance were reported: the administration of RA prevents the development of Alzheimer's pathology and protects neurons from degenerative diseases [32]. The main challenge in pharmacological study is to demonstrate the possible anti-tumor effects of RA on colitis-associated colon cancer [35].

Currently, RA is produced in different countries and by several large industries; an increase of its importance as a healthy compound is defined by the Development Strategy pre- and post-COVID-19 [36].

\subsection{Ulvan}

Ulvan, a water-soluble anionic polysaccharide, is the short designation of a complex sulfated polymer extracted from the cell wall of Ulva species [37,38], commonly known as sea lettuce. Ulva is an abundant and ubiquitous green macroalgae, proposed as a model system with phenotypic plasticity $[39,40]$. The genus Ulva is adapted to various environmental conditions and could be wild-harvested or cultivated regarding ulvan extraction [41-43]. The extraction of the polymer occurs from many different locations around the world, including the species: U. rotundata [44], U. armoricana [44,45], U. rigida [46,47], U. clathrata [48], U. fasciata [49-52], U. intestinalis [53], U. ohnoi [54,55], U. lactuca [56-58], U. pertusa [59], and many others. Despite the dominance of red and brown seaweed production, the particular interest of Ulva is due to its fast growth rates and high ulvan carbohydrate content $[40,60]$. Consequently, the biomass of the Ulva species is emerging as a sustainable raw material, with increasing commercial importance and diversification for the bioeconomy [43].

Ulvan is gelling water-soluble cell-wall acidic polysaccharide [61,62], crosslinked with other components by ionic interactions [38]. While the cell wall polysaccharides represent about $38-54 \%$ of the dry algal matter [38], ulvan is the key polysaccharide present in Ulva sp. ranging up to $29-36 \%$ of dry weight of the macroalgae biomass $[38,63]$.

It is a complex marine xyloglucuronorhamnan, i.e., a heteropolysaccharide composed mainly of xylose and glucuronic acid and includes rare sugars such as rhamnose and iduronic acid within its backbone, conferring a distinct character to the molecule. Variable amounts of other monomers are often reported, such as glucose, arabinose, galactose, mannose $[44,63]$. The structure contains a main repeating disaccharide unit corresponding to two forms of aldobiuronic acids, named as ulvanobiuronic acid A and B for simplicity [64]; moreover, it consists of minor units such as aldobioses, named ulvanobioses or type $\mathrm{U}$ (Figure 4). The detailed chemical analysis shows a branch in the ulvan main chain and minor amounts of branches containing hexose and unsaturated glucuronic acid residue were found $[48,64]$.
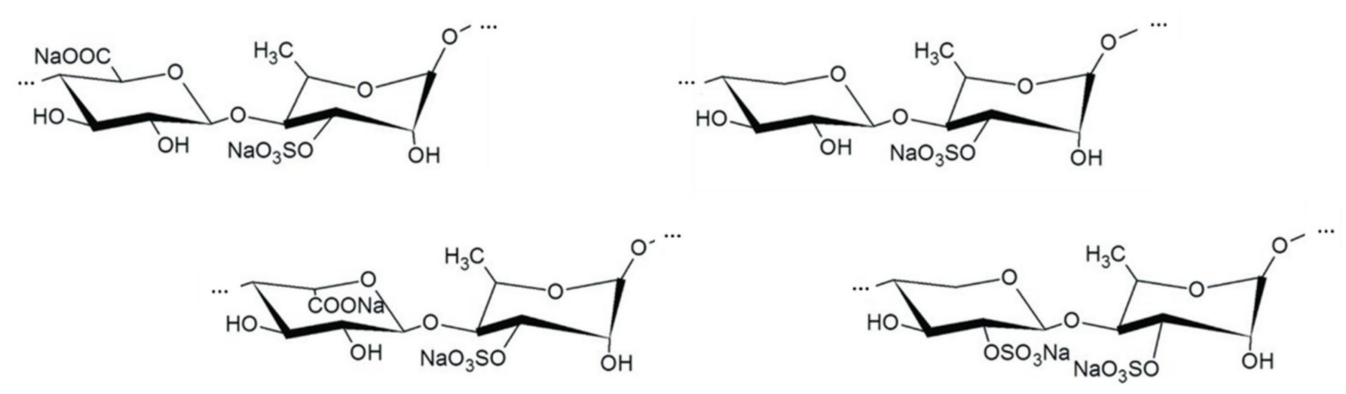

Figure 4. Structure of the main repeating disaccharides units in ulvan: ulvanobiuronic acids and ulvanobiose. 
In contrast to land plants that do not produce sulfated polysaccharides, ulvan contains sulphate groups mainly located at C-3 of $(1 \rightarrow 4)$-linked rhamnose residues [64]. Furthermore xylose-2-sulfate are also described [38] and about $4 \%$ of the xylose moieties bear sulfate groups in ulvan extracted from $U$. clathrata [48]. The total sulfation content varies widely from 2.3 to more than 28-40\% [63] and, according to Figueira et al. [42], ulvan from cultivated $U$. fasciata presented stronger signals of sulphate than natural ones. The sulphate group plays an important role, and the degree of sulfation is usually positively correlated with ulvan bioactivities [63]. The sulphate content is related to antioxidant activity [65], but not related to elicitor activities in suspension-cultured cells or infected Arabidopsis thaliana plants [50,53].

One of the major challenges is the determination of ulvan molecular weight (Mw). Ulvans naturally exhibit a high level of polydispersity and a molecular weight in the range $5.3 \times 10^{4}-1.8 \times 10^{6} \mathrm{~g} / \mathrm{mol}$ is generally obtained. These values reflect the large variations on the Mw values depending on origin, mode of extraction, different methods and determination conditions. The tendency to form microaggregates contributes to the variation [66,67]. Robic and co-workers [68] studied how the stabilization treatments of the $U$. rotundata biomass can impact the ulvan extraction. Frozen and freeze-dried samples yielded polymers with higher Mw that is positively correlated with the gel formation [44]. Molecular weight variations interfere with ulvan biological activities $[69,70]$.

Despite the complexity of the ulvan molecule itself, other factors contribute to the variabilities related to the number of Ulva species such as seasonal period of harvesting, eco-physiological variation, extraction techniques $[63,67]$. The correct identification of Ulva species presents considerable difficulty/confusion because there are many species in nature, and they present intermediate forms with flexibility of the morphology (phenotypic changes under different growth conditions), in growth and metabolite accumulation $[39,60]$. Thus, it is necessary to identify them on the basis of their morphological characteristics and molecular analysis [71].

An interesting feature of the polymer is the ability of gel formation with low intrinsic viscosity in aqueous solution, and the mechanism appears unique among polysaccharide hydrogel [38]. The ultrastructure analysis revealed a hydrophobic and aggregative behavior of ulvan gel that forms bead-like ("raspberry-like") aggregates interconnected by fiber-like constituents. How ulvan is present in the seaweed cell walls is still an open question [61].

Ulvan exhibits many direct biological activities, including antioxidant, immunomodulatory and immunostimulating, cytotoxic and antitumor, anti-inflammatory, anticoagulant, antihyperlipidemic, antiviral, antibacterial and tissue engineering properties as reviewed by Tziveleka et al. [67], Mo'o et al. [72] and Kidgell et al. [70]. Furthermore, the polymer is an elicitor or priming agent with the capacity to modulate cellular signalling in metabolic pathways suitable for plant protection $[73,74]$. The small, non-sulphated oligomers are able to induce oxidative burst in dicot cells [53].

The detailed knowledge of ulvan structures provides the basis for its modification and for the relationship between its chemical structure and biological activity [53]. However, its complex structure remains a challenging aspect of ulvan applications. Future studies should be focused on the structure-activity relationship to obtain more active and well-defined ulvans, resulting in the second generation of molecules [49]. In fact, ulvan is a valuable bio-ingredient and it guides the market to further exploitation for future applications [72]. A pivotal strategy will be to have ulvan as a commercially available source. Currently, at least three companies in the carbohydrate chemistry field provide ulvan polysaccharide as a laboratory reagent for research and innovation development. The emerging demand of the market is indeed the industrial ulvan production, available in high quantity and with a certified quality [66]. However, the standardization of processes and big scale producers are still missing. 
The sum of these characteristics makes ulvan a unique molecule with a broad number of biological and biomedical applications. In fact, there are different possibilities to include ulvan for the preparation of biomaterials or hybrid biomaterials: membrane, particles, hydrogels, films, scaffolds, nanofibers, stabilizer emulsifier, adsorbents $[67,75,76]$.

\section{Extractions Processes}

\subsection{RA Extraction}

Together with plant conservation after harvesting, the extraction process is the most critical step for obtaining significant amounts of biologically active polyphenolic compounds. The method of choice is driven by the stability and solubility of the compounds of interest, as well as by the desired scalability of the entire process.

Traditional methods are based on the extraction of the compounds after the diffusion of a solvent in the plant matrix, and comprise maceration, infusion, heat reflux (HRE), and Soxhlet extraction. Due to its chemical structure, RA is conventionally extracted by methanol, acetone, ethanol, water, or a mixture of them. A percentage of water from 10 up to $70 \%$ is required for an efficient extraction of polyphenolic compounds as it could increase the diffusion of polyphenols from plant cells through the swelling effect on the plant tissues. More sophisticated techniques have been introduced with the aim of reducing solvent consumption and avoiding unnecessary losses of energy and time, thus reducing the overall cost of the procedure and its environmental impact. Among the most modern methods, supercritical fluid extraction, pressurized liquid extraction, and ultrasound-assisted (UAE) and microwave-assisted extraction (MAE) can be numbered.

Numerous papers regarding the extraction of RA have been recently reviewed by Ngo et al. [77]. Here, we will discuss those papers reporting the direct comparison among different extraction techniques. In the following studies, the extraction yield (i.e., extracted mass vs. sample mass) and in some cases the extraction selectivity, were taken into consideration as main parameters to be optimized during the extraction process.

Jacotet-Navarro and coworkers [78] compared the performances of six different configurations of ultrasound (bath, reactor, and probe) and microwave (reflux under microwave, microwave under nitrogen pressure and microwave under vapor pressure) based processes for the extraction of rosmarinic, carnosic and ursolic acids from rosemary. All processes used a mixture of ethanol/water $(90 / 10, v / v)$, and the results (in terms of extraction yield, purity, and content in each of compound) were compared to conventional HRE and maceration. Extraction temperature was set at $78^{\circ} \mathrm{C}$, room temperature, $40^{\circ} \mathrm{C}$ and $70{ }^{\circ} \mathrm{C}$ (or higher) for HRE, maceration, $\mathrm{UAE}$, and MAE, respectively, and time was fixed at $30 \mathrm{~min}$. The lowest total extraction yields were obtained with maceration and ultrasounds, which the authors attributed to temperature difference during extraction. MAE at $150{ }^{\circ} \mathrm{C}$ gave the highest total yield, but looking at the single compounds, RA was extracted in lower amounts with respect to carnosic and ursolic acid. The authors attributed this result to the extraction solvent, since RA is more soluble in water, whereas the other two compounds are more soluble in ethanol. The most suitable extraction methods for RA are confirmed as MAE at $125^{\circ} \mathrm{C}$ or $150{ }^{\circ} \mathrm{C}$, or conventional HRE extended up to $5 \mathrm{~h}$, which indicates also that RA is not a thermo-sensitive compound. However, in terms of energy consumption and carbon emission, HRE prolonged for $5 \mathrm{~h}$ showed the highest energy-consumption (850 kWh/kg extract) and carbon emission (680 $\mathrm{kg} \mathrm{CO}_{2} / \mathrm{kg}$ extract).

In a similar study conducted in 2014 [79] on $R$. officinalis leaves, different alkanol/aqueous mixtures in combination with Soxhlet extraction, MAE and UAE were evaluated. Different ultrasounds and microwaves operating conditions were studied. Both MAE and UAE were able to provide a three- and two-fold enhancement, respectively, with respect to hot percolation. Curiously, MAE provided the best result with $70 \%$ aqueous ethanol, while UAE yield was optimal with $70 \%$ aqueous methanol.

Herrero et al. [80] compared pressurized liquid extraction (PLE), using water and ethanol as solvents, supercritical fluid extraction (SFE), using neat $\mathrm{CO}_{2}$ and supercritical $\mathrm{CO}_{2}$ modified with ethanol, water extraction and particle formation on-line (WEPO). In 
WEPO, a first dynamic subcritical water extraction (SWE) is followed by extract drying under hot $\mathrm{N}_{2}\left(70^{\circ} \mathrm{C}\right)$ with supercritical $\mathrm{CO}_{2}$ assisted nebulization. The second step allows the precipitation of the extracts, which forms particles with variable diameter, depending on the drying conditions. Compared to single step SWE, with WEPO the extraction yield was lower (but still higher respect to SFA), probably because of the absence of an equilibration step, but it is compensated by the elimination of any lyophilization procedure. Comparing the three techniques, PLE using water was able to maximize both the extraction yield and the antioxidant activity.

A systematic work published in 2020 [81] discussed the extraction efficiency of RA from Lamiaceae herbs (lemon balm, peppermint, oregano, rosemary, sage, and thyme) using various extraction techniques (maceration with stirring, HRE and MAE) and extraction conditions (solvent acidity, solvent type, extraction time and temperature). The authors found that solvent acidity was the parameter which most significantly affected the recovery of RA, regardless the extraction technology.

In most of the works found in the literature, a One Variable at a Time (OVAT) methodology was used to optimize RA extraction. This approach, however, does not consider the interactions among extraction parameters and does not assure the maximization of the extraction yield. In 2017, Caleja et al. [82] compared, for the treatment of Melissa officinalis, HRE, MAE and UAE performances through response surface analysis. A circumscribed central composite design of three variables (time, temperature, and ethanol-water proportion) with five levels was used to maximize three response values (mg RA/g plant DW, mg RA/g extracted residue, and g extracted residue/g plant DW), and optimal variable conditions were found for each extraction technology. UAE emerged as the most efficient method, apparently in contrast with previous studies, which revealed a higher yield for MAE but obtained with water as extraction solvent and under conditions not properly optimized.

The studies discussed so far made use of dry rosemary leaves, eventually cryogenically grinded. Rodríguez-Rojo and co-workers [83] studied, together with the role of the extraction process, the influence of different pre-treatments (de-oiling, de-oiling and milling) for RA recovery with pure water from rosemary. Plant pre-treatments are aimed at maximizing the extraction efficiency and at overcoming inner mass transfer limitations by reducing particle size and by breaking cell membranes, to facilitate the access of the solvent. With both pre-treatments, water extraction showed significantly better yields than extraction with ethanol, regardless of the chosen extraction technique (conventional, MAE and UAE). By DPPH assay, the authors found also that in aqueous systems, RA shows an antioxidant activity superior, with respect to lipid environments.

\subsection{Ulvan Extraction}

Ulvans differ in their molecular weight, sugar composition, and sulfation ratio; these factors influence the biological properties. Therefore, increasingly sensitive, and reliable analytical methods, the mechanisms by which ulvan interferes with the different biological systems, and the knowledge of the smallest structure required for bioactivity have induced companies to produce well-defined ulvans (second generation). The extraction method, chemical characterization and quantity need to be considered for industrial production. However, much effort is currently required to explore the structural diversity of the ulvan broad family for an industrial perspective in relation to its biological properties. Since ulvan is a complex polymer associated to proteins and with others cell-wall components of Ulva [38], the ulvan extraction procedure is a critical point.

Maceration or Soxhlet extraction with solvents (ethanol or methanol) are important steps for defatting the macroalgae material to remove amino acids, peptides, lipids, and pigments. They are used as conditions to obtain high pure molecular weight and better extraction yields from 2.8 to $13.8 \%$ [84]. Alternatively, algae powder can be incubated $24 \mathrm{~h}$ with acetone to remove lipids and pigments [85]. However, Kidgell et al. [63] considered that such pre-treatments have no effect on either extraction efficiency or the quality of ulvan extracted and for this reason are considered unnecessary. 
To enhance extraction efficiency and to provide better ulvan yield, Ulva biomass is dried in air at $70{ }^{\circ} \mathrm{C}$ [68] and finely milled to obtain high recovery and pure product [63]. The maximum ulvan extraction efficiency depends also on the active growing period of the macroalgae [44]. Ulva is usually obtained with hot water in the autoclave for $1-2 \mathrm{~h}$ at 90 or $110{ }^{\circ} \mathrm{C}(1.97 \mathrm{~atm})$ or heated $(1,2$ or $3 \mathrm{~h})[63,67]$. The extraction is improved by the presence of divalent cation chelating agents, such as ammonium oxalate or sodium oxalate [68]. The extract can be treated with enzymes such as protease (proteinase K) for proteolytic digestion to remove contaminants [86]. Other methods include multilevel extraction procedures, using water followed by the addition of $\mathrm{NaCO}_{3}$ and $\mathrm{NaOH}$ or acid solutions and ammonium oxalate, but the stability may be decreased at low $\mathrm{pH}$ [72]. The extract is separated from the biomass by filtration and/or centrifugation. Regardless of the extraction method, precipitation of ulvan is achieved by adding 2-2.5 volumes of ethanol (70 or $96 \%$, cold or not) and is the most common method used in the laboratory to recover the polymer, while ethanol-soluble compounds, such as metabolites, remain in solution. Although ethanol precipitation is a suitable method, it is limited by the low solubility of salts and high solubility of low molecular weight ulvan in ethanol-water mixtures. Later, the ulvan aqueous extract is filtered, concentrated in a rotary evaporator, and air-dried or even freeze-dried [67]. As a final step, the precipitation methods are followed by efficient desalting and removal of small molecules contaminants by dialysis membrane, ultrafiltration, or even chromatography [63].

\section{Bionanosystems}

Incorporation of bioactive compounds, such as natural polyphenols, in micro- or nano-encapsulating systems is a strategy to protect these substances against undesired environmental conditions (e.g., light, heat, humidity), improve solubility and bioavailability, and enable their controlled release and target delivery [87]. These effects are achieved due to the small size and high surface-to-volume ratio of the carriers, as well as the physical and chemical interactions between the bioactive compound and the encapsulating material [88].

\subsection{Bionanosystems for $R A$}

As discussed in the previous paragraphs, RA is a phenolic molecule with numerous possible applications in the food and pharmaceutical industries due to its antioxidant, antimicrobial, and anti-inflammatory properties. However, RA has low lipophilicity reflected in reduced transmembrane penetration and poor oral availability $[89,90]$. Furthermore, it is unstable, poorly soluble in water, and its low partition coefficient limits its transport across biological barriers, as well as its inclusion in a cosmetic formulation and efficacy as an antioxidant [91]. In addition, the acidic environment and enzymes present in the human digestive tract or in many food products impact its stability resulting in low bioavailability and reduced biological activities [92]. To increase the RA stability, as well as its permeability and thus bioavailability, a viable method is its incorporation into micro- or nanosystems.

Many different carriers have been tested so far for the encapsulation of polyphenols, including a wide variety of natural and synthetic polymers. The most commonly used encapsulating materials include polysaccharides (i.e., chitosan, cyclodextrins, alginate gel), lipids (waxes, paraffin, oils), bio-based polyesters (i.e., poly(lactic acid), poly(lactic co-glycolic acid)), acrylic polymers, polycaprolactone, and also inorganic materials (i.e., anionic and cationic clays, halloysite, silica nanoparticles) $[15,93,94]$.

Selected examples are discussed below about the encapsulation/immobilization of RA into different types of carriers, organic and inorganic, aiming to improve its stability, permeability, and bioavailability. 


\subsubsection{Bionanosystems Based on Organic Carriers}

Most of the examples reported in the literature about the immobilization of RA involve the use of polymer-based micro or nanosystems (Table 1). Generally, natural polymers and biodegradable polymers are selected as the preferred encapsulating materials for applications in the field of skin delivery systems. In fact, these materials are non-toxic, non-reactive in contact with human tissues and can be broken down or metabolized and removed from the body through normal metabolic pathways. Furthermore, their properties depend on the structural features, including composition, molecular weight, and nature of chain end groups. In addition, these polymers can be chemically functionalized to achieve improved properties [15].

Among the different natural polymers used as entrapping materials, chitosan (CS), which is a natural, biodegradable, and hydrophilic polysaccharide, is the one that has been most investigated for encapsulating polyphenols including RA, because it behaves as a stable and protective vehicle to deliver active molecules. Microparticles of CS are very effective as encapsulating systems for bioactive compounds because they are stable in contact with fluids and physiological barriers, protect active compounds from adverse conditions, and can control their release. The properties of the microparticles depend on the molecular weight of the chitosan, the degree of deacetylation, and the mass ratio of chitosan to active ingredient. Many polyphenols are insoluble in water, but through encapsulation in CS microparticles can be delivered topically. In addition, these systems have also been successfully tested for oral and transmucosal delivery of the active ingredient, and in other biomedical, pharmaceutical and food applications, for delivery of natural antioxidants [15,93,95-97]. Casanova et al. [91] first encapsulated RA in microparticles of CS and modified-CS (functionalized with carboxylic acid groups that make it more water soluble) prepared by a spray drying process for skin delivery in cosmetic formulations. Spherical RA-loaded microparticles with an average diameter of $4.2 \mu \mathrm{m}$ and $7.7 \mu \mathrm{m}$ were obtained using CS or modified-CS, respectively. Modified-CS/RA particles showed slower RA release in coconut oil ( $\approx 75 \%$ after $2 \mathrm{~h}$ ) than in water ( $\mathrm{pH} 5.5)(\approx 100 \%$ at $30 \mathrm{~min})$, while CS/RA microparticles revealed a fast release of RA $(\approx 90 \%$ after $45 \mathrm{~min})$ in both media (Figure 5$)$. This effect was due to the high solubility of the modified-CS in water, which promoted complete disintegration of the microparticles and fast release of RA. Otherwise, modified-CS nanoparticles were less soluble in oil, and consequently RA was trapped longer and released more slowly.
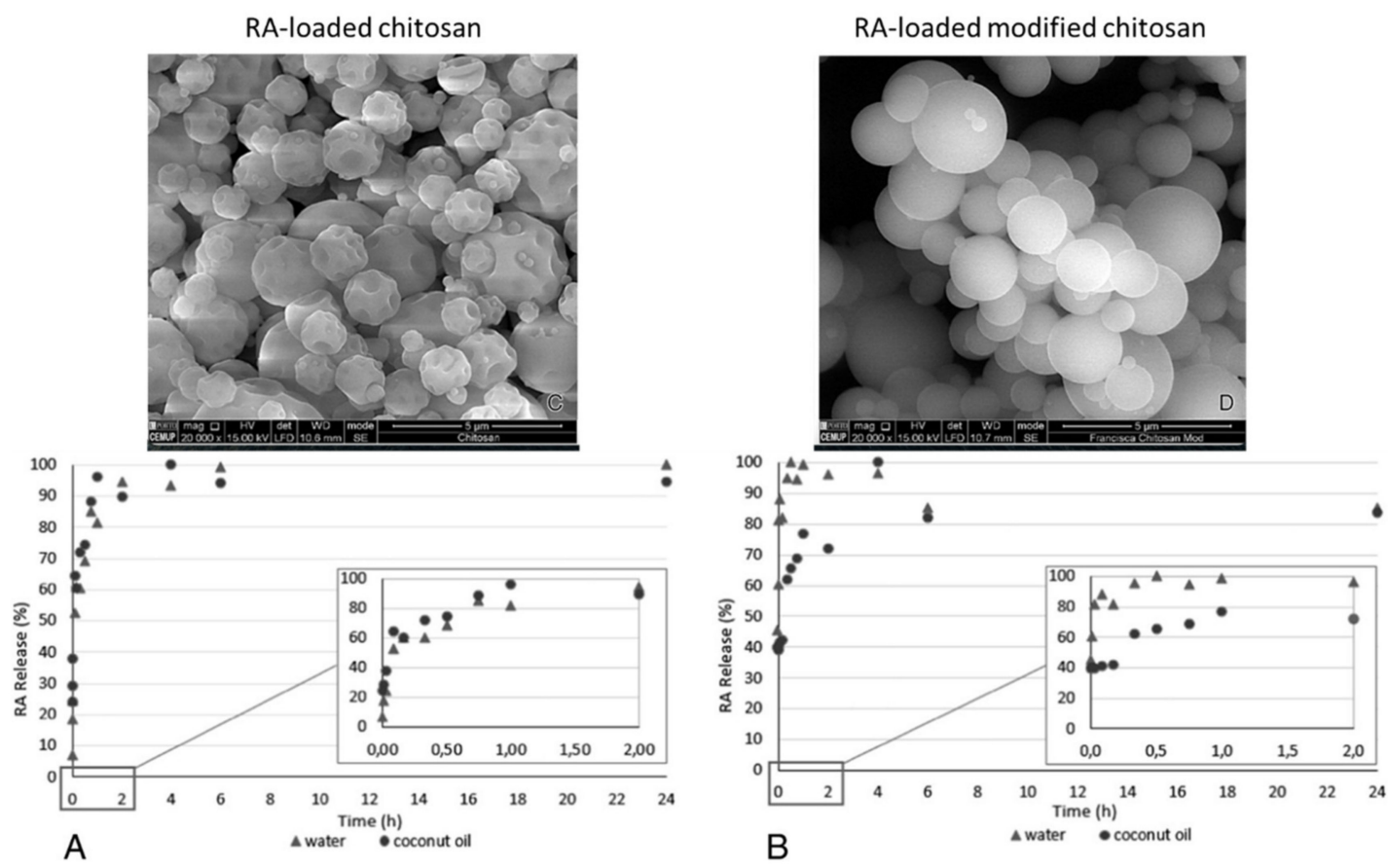

Figure 5. SEM micrographs and RA release profile in water and coconut oil of RA-loaded chitosan (A) and RA-loaded modified chitosan (B) microparticles (adapted from Casanova et al. [91], copyright 2016 Elsevier). 
CS nanoparticles have also been investigated for encapsulating RA or RA-containing extracts $[98,99]$ due to their exceptional ability to release drugs, especially at the mucosal level. Therefore, the encapsulation of antioxidant molecules in CS nanoparticles represents a possible therapy towards the treatment of several chronic diseases characterized by oxidative stress. For example, da Silva et al. reported the preparation of CS nanoparticles by ionic gelation of CS and sodium tripolyphosphate in solution and their use as biodegradable mucoadhesive nanocarriers of RA and RA-containing extracts from Salvia officinalis (sage) and Satureja montana (savory) [95,98]. The antioxidant compounds were successfully encapsulated in CS nanoparticles of 200-300 nm, demonstrating the absence of chemical interactions between the antioxidant and CS and showing good release of RA and appreciable antioxidant activity. Furthermore, the authors demonstrated that RA-loaded CS nanoparticles were safe without relevant cytotoxicity against retinal pigment epithelium and human corneal cell line, thus making these nanoparticles very promising drug delivery systems for ocular application in oxidative eye conditions. Madureira et al. [99] later demonstrated that RA-loaded nanoparticles with zeta potential of $20-30 \mathrm{mV}$ are suitable to adhere to the intestinal epithelium, releasing the antimicrobial compound to the gut and preventing or controlling intestinal disorders provoked by bacterial food pathogens (i.e., Bacillus cereus, Escherichia coli O157, Listeria innocua, Staphylococcus aureus, Salmonella typhimurium, and Yersinia enterocolitica). As an alternative to encapsulation in spherical CS particles, adsorption of RA on CS powder was also studied, obtaining waterinsoluble RA-CS complexes characterized by a high amount of immobilized RA [100,101]. From kinetic studies it was established that the adsorption of RA on CS powder occurred in two steps: in the first step RA molecules were attached to the ionized amine groups on the surface of the CS powder due to electrostatic interaction, while in the next step the previously adsorbed RA molecules became the sites for adsorption of additional RA molecules due to hydrophobic interaction. Furthermore, this study revealed an interesting aspect; that of the fluorescence of aqueous dispersions of RA-loaded powders. The authors showed that as the amount of RA adsorbed on the CS powder increases, the fluorescence emission maximum shifts towards shorter wavelengths, suggesting a stronger association of RA molecules on the surface of the CS powder [102]. Interestingly, Chhabra et al. [103] prepared RA-loaded chitosan encapsulated graphene nanoparticles and demonstrated that this combination has high in vitro antibacterial activity, and it is efficacious for wound healing treatment. Furthermore, chitosan was combined with zinc oxide and the biocompatible nanoparticles were successfully used to preconcentrate and recover RA in complicated matrices, such as the extracts of medical plants [104], by dispersive micro-solid phase extraction.

Cyclodextrins (CDs) are another example of natural polymers successfully used for encapsulating polyphenols $[105,106]$. CDs are cyclic oligosaccharides soluble in water with an inner hydrophobic core and a hydrophilic exterior, which can be used as hostnanosystems [107]. Indeed, the hydrophobic cavity (diameter about $0.60 \mathrm{~nm}$ ) can act as a host entrapping polyphenols and terpenes, thereby improving solubility in water, increasing chemical and physical stability, and, in a few cases, enhancing the activity of guest molecules. Molecules such as gallic acid, (-)-epigallocatechin, (-)-epigallocatechin-gallate, quercetin, chlorogenic and caffeic acids, and also RA were successfully encapsulated in CDs [108-110]. Fateminasab et al. [109] showed that RA can be encapsulated into the cavities of $\beta$ - and $\gamma$-CDs, leading to water-soluble and photo-stable inclusion complexes. In these systems, the complementary use of 1D and 2D-ROESY NMR and capillary electrophoresis demonstrated that RA and $\beta-C D$ form a stable complex and that catechol subunits of RA are inserted inside the CD hydrophobic cavity, while no interactions of RA with the outside of the CD unit could be reliably detected. The results suggest that this conformation can improve the thermo-oxidative stability of RA and modulate its release as a function of $\mathrm{pH}$ [108]. The complexation of RA with $\alpha-C D, \beta-C D$ and with differently functionalized CDs revealed an increment of the RA water solubility with an increase in the fluorescence intensity and a blue shift of the emission maximum (Figure 6). In addition, 
the antioxidant capacity of RA also increased for RA-CD complexes, which was interpreted as the stabilization of the 1-e oxidized catechol moiety of RA by enhanced intramolecular H-bonding [111].

(A)
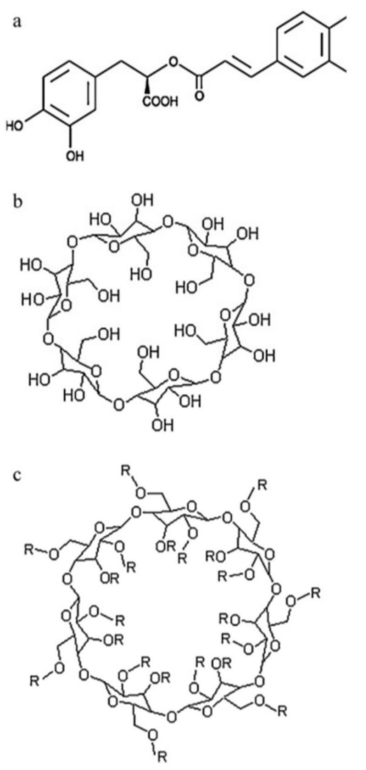
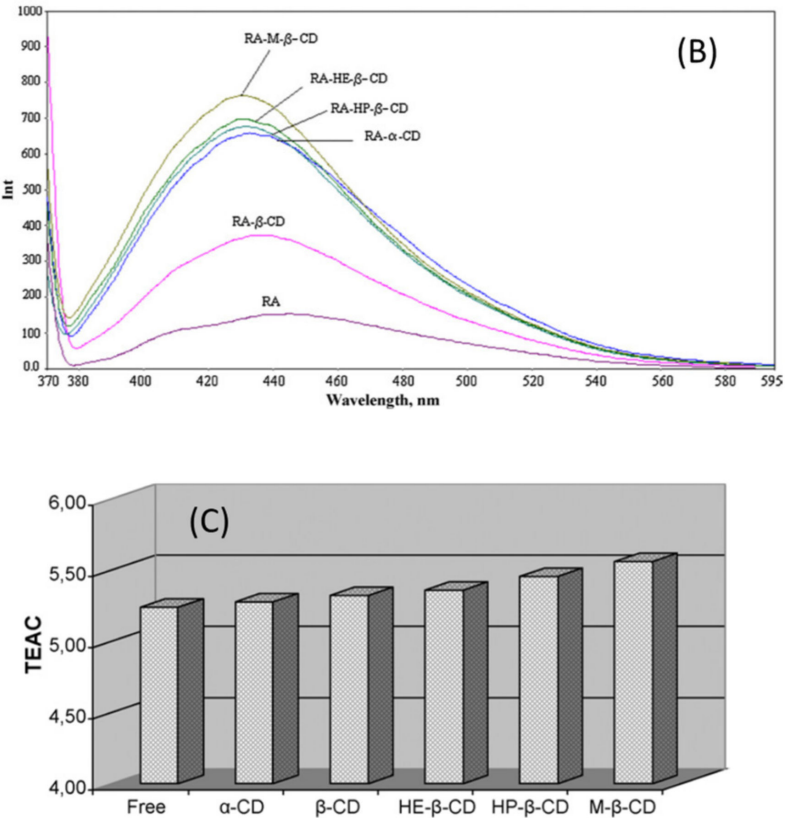

Figure 6. (A) Molecular structures of the guest and hosts in RA-CD complexation: (a) RA, (b) $\alpha$-CD and (c) $\beta-C D(R=H)$ and its derivatives. (B) Fluorescence spectra of RA in aqueous solution with different $\mathrm{CDs}$ at $\mathrm{pH}$ 7.0. (C) Trolox equivalent antioxidant capacity (TEAC) of RA in free and complex forms in aqueous solutions at pH 7.0 (adapted from Celik et al. [111], copyright 2011 Elsevier).

Alginate beads can be also used as RA nanocarriers. For example, Rijo et al. demonstrated the efficiency of alginate beads in encapsulating aqueous extracts of Plectranthus plants, having RA and caffeic acid as major components [112,113]. The authors demonstrated that alginate-based bionanosystems retain a high amount of RA and caffeic acid, are excellent inhibitors of acetylcholinesterase, and have good antioxidant capability. All these features indicate that this strategy could potentiate the action of plant extracts by promoting a protective effect and a sustained release of active constituents and, ultimately, improve their pharmacological effects. Similar results were found by Stojanovic et al. [114] that investigated the encapsulation of thyme aqueous extract containing RA in calcium alginate gel beads prepared by electrostatic droplet generation (electrostatic extrusion). Additionally, in this case, it was demonstrated that the encapsulation preserved the bioactive compounds as the total antioxidant content remained unchanged.

Another interesting example of RA immobilization for food and pharmaceutical packaging is that proposed by Ge et al. [115] that prepared gelatin-based edible films containing RA for effective antioxidant and long-term antibacterial activities. In this case, RA was covalently bonded to the carrier. Indeed, the first RA was conjugated onto a gelatin backbone via the carbodiimide (EDC)/N-hydroxysuccinimide (NHS) method (Figure 7) and later the conjugates were plasticized by glycerol and crosslinked by dialdehyde xanthan gum to fabricate active RA-gelatin edible films. The results indicated that the RA-gelatin edible films present good water resistance properties, strong mechanical properties, and excellent ultraviolet light barrier ability. The conjugation of RA conferred gelatin-based edible films with effective antioxidant and antibacterial activities, which was maintained for 3 months. 

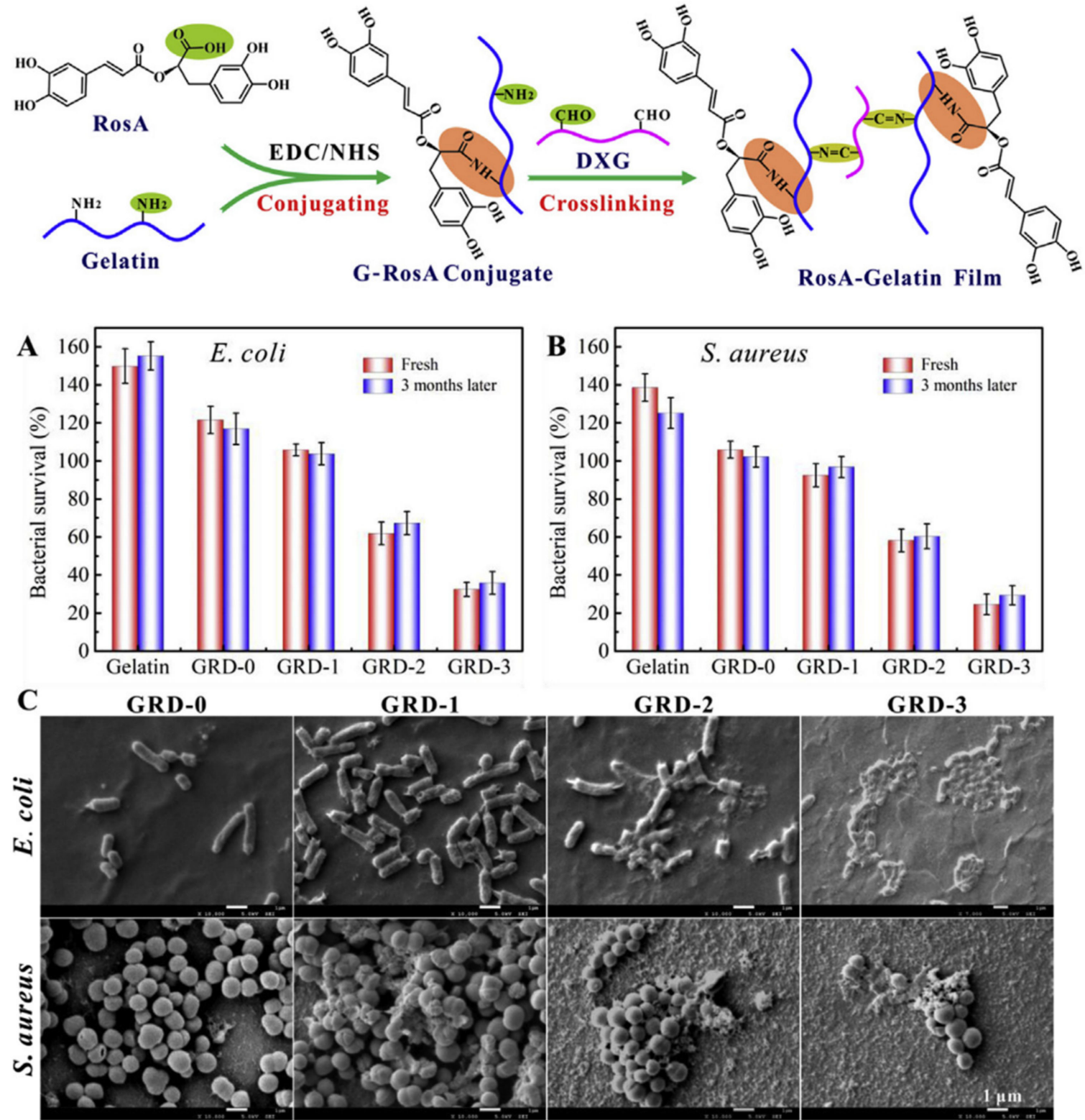

Figure 7. Scheme of preparation of RA-gelatin film. Survival rates of E. coli (A) and S. aureus (B) after treating with newly prepared (red histogram) and 3 months stored (blue histogram) gelatin-based edible films for $24 \mathrm{~h}$ at $37^{\circ} \mathrm{C}$. (C) SEM images of E. coli and S. aureus after treating with gelatin-based edible films for $24 \mathrm{~h}$ at $37^{\circ} \mathrm{C}$ (adapted from Ge et al. [115], copyright 2018 Elsevier).

Sahiner et al. [92] prepared crosslinked poly(RA) particles by an emulsion crosslinking process (Figure 8) and found that poly(RA) particles can release RA in acidic, neutral and basic environments, and that the antioxidant activity of poly(RA) is almost indistinguishable from that of pure RA. In addition, poly(RA) particles were $\sim 66 \%$ less cytotoxic to mammalian cells than RA monomer and showed a strong inhibition of $\alpha$ glycosidase for possible application in the treatment of diabetes. 


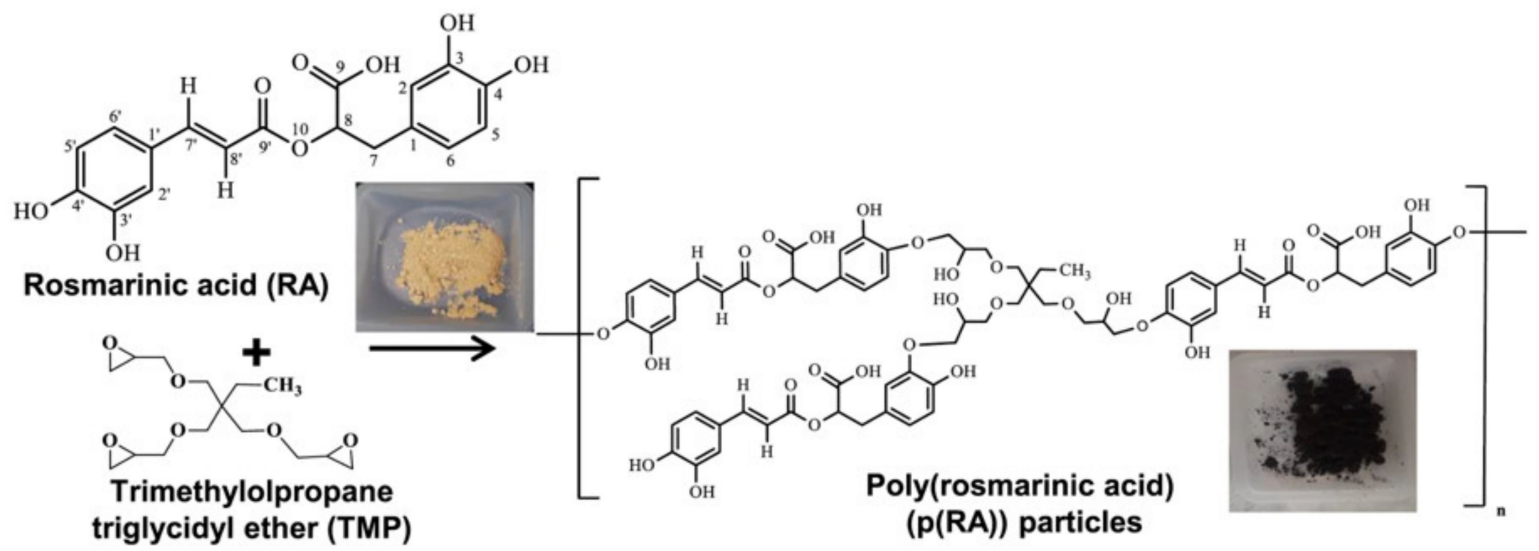

Figure 8. Chemical structure and digital camera image of RA and poly(RA) particles (adapted from Sahiner et al. [92], copyright 2019 Elsevier).

Gimenez-Rota et al. [116] described the encapsulation of RA into polylactic-co-glycolic acid (PLGA) and poly-lactic acid (PLA) carriers (with size ranging between $1.5 \pm 0.5 \mu \mathrm{m}$ and $0.3 \pm 0.1 \mu \mathrm{m})$ in combination with $\beta$-carotene $(\beta-\mathrm{CA})$ and tocopherol $(\alpha-\mathrm{TOC})$ and using supercritical emulsion extraction technique for the preparation. RA and $\alpha$-TOC were added to the formulation as extra protectors of the light-sensitive $\beta$-CA thus improving its shelf-life. Results showed that the encapsulation efficiency of RA in both PLA and PLGA was very low; between 1.3 and $3.9 \%$, but it increased by co-encapsulation of RA with $\beta$-CA and $\alpha$-TOC. However, the inclusion of RA in the emulsion formulation caused a further reduction in $\beta$-CA encapsulation efficiency because of the high solubility of RA into the high-pressure mixture of carbon dioxide and organic solvent formed during the emulsion extraction. Among the synthetic polymers used as nanocarriers of RA, Kim et al. [93] prepared RA-loaded polycaprolactone (PCL) microspheres using the emulsion solvent evaporation method. It was demonstrated later that cream formulations containing RA-loaded PCL microspheres have a better long-term stability of RA compared with those containing only RA.

Another very interesting method for the encapsulation of plant extracts is the one involving the electrospinning of poly (3-hydroxybutyrate-co-3-hydroxyvalerate) (PHBV) solutions containing rosemary extract and green tea extract obtaining ultrathin fibers [117]. Continuous films produced by the annealing of resultant electrospun mats showed antimicrobial and antioxidant activity in both open and closed systems. It was found that the antimicrobial activity was higher in the case of the closed system due to the presence of volatiles stored in the headspace. However, the antioxidant activity of the fibers and films was much lower than that of the neat active substances, which was related to the entrapment and loss during electrospinning and film processing, and which was also reduced with the passage of days due to the continuous release of the active compounds.

Lipid nanotechnology-based systems are another interesting route to encapsulate RA and other plant extracts for drug delivery. For example, RA, due to its physicochemical properties, has low skin penetration efficiency, but its encapsulation in liposomes [118], ethosomes [119] and ultra-deformable liposomes containing fatty acids [120] can increase its transdermal penetration. Liposomes are micro or nanosized spherical vesicles composed of one or more lipid layers containing an aqueous phase. They can also carry both hydrophilic and lipophilic drugs. Due to the presence of phospholipids in their structures, they are similar to biological membranes. Liposomes made of 1:1 Phospholipon $90 \mathrm{H}$ and 1,2-dimyristoyl-sn-glycero-3-phospho-(1'-rac-glycerol) sodium salt loaded with oregano extract containing RA and carvacrol showed an encapsulation efficiency of RA of about $60-70 \%$, and about $80 \%$ of RA was released during in vitro test [118]. 
Ethosomes are vesicular systems composed of phospholipids, ethanol, and a high-water concentration, are very flexible, and can very easily penetrate inside the deep skin layers. Ethosomes prepared using $30 \% w / v$ of ethanol and $2 \% w / v$ of soya phosphatidylcholine loaded with RA with a particle size of $192 \pm 1.95 \mathrm{~nm}$, zeta potential of $-32.1 \pm 2.37 \mathrm{mV}$, polydispersity index of $0.215 \pm 0.005$ and an encapsulation efficiency of $66 \pm 1.51 \%$ were compared with liposomes made of dipalmitoyl phosphatidylcholine with a particle size of $202 \pm 1.12 \mathrm{~nm}$, zeta potential of $-11.2 \pm 1.15 \mathrm{mV}$, polydispersity index of $0.220 \pm 0.050$ and encapsulation efficiency of $62 \pm 1.95 \%$. RA-loaded ethosomes and liposomes maintained the antioxidant, anti-collagenase, and anti-elastase effect characteristic of RA. Both ethosomes and liposomes significantly increased RA skin penetration, but ethosomes have been found to be much more efficient than liposomes for delivering the drug to the deeper layer of skin [119].

Finally, ultra-deformable liposomes (ULs) are elastic liposomes generated by the addition of edge activators to liposomes, and those containing fatty acids show high efficiency in skin penetration. ULs prepared by using $0.69 \% w / v$ of Phospholipon 90G, $0.078 \% w / v$ of cholesterol, $2 \% w / v$ of Tween 20 (non-ionic surfactant), $0.5 \% w / v$ of oleic acid and water had particle size of $60 \pm 17.3 \mathrm{~nm}$, polydispersity of $0.32 \pm 0.1$ and zeta potential of $-18.03 \pm 0.35 \mathrm{mV}$. The confocal laser scanning microscopy, where the colocalization technique using multifluorescent labelled particles was utilized, showed that ULs attached to any part of the skin before releasing the entrapped drug to further penetrate the skin [120].

Solid lipid nanoparticles (SLNs), made of lipids that remain solid at both the temperature of the human body and at room temperature, are another way to encapsulate RA. The composition of these nanoparticles, along with their characteristics, makes the SLNs ideal for carrying/delivering sensitive bioactive compounds. SLNs protect these compounds against chemical degradation and facilitate their application in varied administration routes [121]. RA was successfully encapsulated in SLNs made of witepsol (mixture of mono-, di- and triglycerides from natural origin) and carnauba wax. About $40-60 \%$ of RA encapsulated in SLNs was released in simulated gastrointestinal tract conditions, and its antioxidant activity was maintained [122]. Another application of RA-loaded SNLs is in the therapeutic approach for neurodegenerative disorders. Indeed, RA, besides having anti-inflammatory and antioxidant activities, also has a neuroprotective effect. In the therapy of neurodegenerative disorders, solid lipid nanoparticles were used for the nasal administration because this is an efficient root for the delivery of active principle to the central nervous system [123]. For the management of Huntington's disease, a neurogenerative disease, the RA-loaded SLNs was prepared using glycerol monostearate as lipid, tween 80 and soya lecithin as surfactant and hydrogenated soya phosphatidyl choline as a stabilizer. Optimized RA-loaded SLNs have the mean size of $149.2 \pm 3.2 \mathrm{~nm}$, zeta potential of $-38.27 \mathrm{mV}$ and entrapment efficiency of $61.9 \pm 2.2 \%$. Nasal delivery of the developed formulation shows that RA-loaded SLNs formulation following the non-invasive nose-to-brain drug delivery is a promising therapeutic approach for the effective management in Huntington disease [124].

Another lipid system used to entrap plant extracts containing RA is the nanostructured lipid carrier (NLC), which has been developed and used as an alternative carrier system to liposomes, emulsions, and solid lipid nanoparticles. Compared to SLNs, NLCs have a higher loading capacity of active ingredients because the liquid lipid in the formulation caused imperfect structures with low crystallization ability than SLNs. Moreover, the firmer inclusion of the active ingredients inside the particle matrix leads to better stability and longer shelf life of entrapped extract [121]. Ocimum sanctum extract containing a high amount of RA was successfully loaded in a NLC made of $5 \% w / w$ of cetyl palmitate, $3 \% w / w$ of tea seed oil, $2.5 \% w / w$ of Plantacare $2000^{\circledR}$ (non-ionic surfactant), and $91.5 \% w / w$ of distilled water. The NLC has an internal droplet size of $261.0 \pm 5.3 \mathrm{~nm}$, poly dispersity index of $0.216 \pm 0.042$, and Zeta potential of $-45.4 \pm 2.4 \mathrm{mV}$. The loaded-RA NLC dissolved in propylene glycol showed a continuous release of RA during $24 \mathrm{~h}$; about $27 \%$ of the extract was detected into the skin layers, and no irritation was detected by Hen's Egg Test on the Chorioallantoic Membrane (HET-CAM) [125]. 
Finally, nanoemulsions containing RA have been developed and tested for different applications. For example, they were used for a new nasally delivered neuroprotective therapy. Here, the association of lipid nanotechnology-based delivery systems with a mucoadhesive biopolymer such as CS improves RA penetration through biological barriers and increases its residence time in the nasal cavity [126]. In another example, nanoemulsion containing RA dispersed in hydrogel made of hydroxyethyl cellulose was tested for topical application. The hydrogel was used as a thickening agent to increase the intrinsic low viscosity of nanoemulsions and improve their stability by reducing the surface and interfacial tension. Hydrogel of RA-loaded nanoemulsions were prepared by using $2.5 \%$ $w / v$ of egg-lecithin, $6 \% w / v$ of medium chain triglyceride (MCT), water $1 \% w / v$ of Tween ${ }^{\circledR}$ 80 (polysorbate 80) a nonionic surfactant and dispersed in hydroxyethyl cellulose. In-vitro RA release studies performed in a Franz type diffusion cell showed that about $60 \%$ of RA is released in $8 \mathrm{~h}$ and skin retention studies evidenced that $0.65 \pm 0.08 \mu \mathrm{g} / \mathrm{cm}^{2}$ of RA were retained in total skin [127].

Table 1. Encapsulation of RA in in organic nano and microsystems.

\begin{tabular}{|c|c|c|c|}
\hline Type of Carrier & Host-Guest System & Main Features & Refs. \\
\hline $\begin{array}{l}\text { Chitosan (CS) } \\
\text { microparticles }\end{array}$ & $\begin{array}{l}\text { RA-loaded CS } \\
\text { microparticles }\end{array}$ & $\begin{array}{l}\text { - } \quad \text { Slower RA release in oil from } \\
\text { modified CS microparticles; } \\
\text { bionanosystems for skin delivery in } \\
\text { cosmetic formulations. }\end{array}$ & [91] \\
\hline $\begin{array}{l}\text { Chitosan }(C S) \\
\text { nanoparticles }\end{array}$ & $\begin{array}{l}\text { RA-loaded CS } \\
\text { nanoparticles }\end{array}$ & $\begin{array}{l}\text { - Good release of RA and appreciable } \\
\text { antioxidant activity; } \\
\text { safe bionanosystems, no cytotoxicity } \\
\text { against retinal pigment epithelium } \\
\text { and human corneal cell line; } \\
\text { application as protectors of } \\
\text { intestinal epithelium and as } \\
\text { delivery systems for ocular therapy. }\end{array}$ & {$[87,88]$} \\
\hline $\begin{array}{l}\text { Chitosan }(\mathrm{CS}) \\
\text { powder }\end{array}$ & $\begin{array}{l}\text { Water-insoluble } \\
\text { RA-CS complexes }\end{array}$ & $\begin{array}{l}\text { - High amount of RA adsorbed on } \\
\text { CS powder. }\end{array}$ & {$[100,102]$} \\
\hline $\begin{array}{l}\text { Chitosan }(\mathrm{CS}) \\
\text { nanoparticles } \\
\text { and graphene }\end{array}$ & $\begin{array}{l}\text { RA-loaded CS } \\
\text { encapsulated graphene } \\
\text { nanoparticles }\end{array}$ & $\begin{array}{l}\text { - High in vitro antibacterial activity } \\
\text { and efficacy for wound } \\
\text { healing treatment. }\end{array}$ & [103] \\
\hline $\begin{array}{l}\text { Chitosan (CS)-zinc oxide } \\
\text { nanoparticles }\end{array}$ & $\begin{array}{l}\text { RA-loaded CS-ZnO } \\
\text { nanoparticles }\end{array}$ & $\begin{array}{l}\text { - Preconcentration and recovering of } \\
\text { RA in complicated matrices by } \\
\text { dispersive micro-solid } \\
\text { phase extraction. }\end{array}$ & [104] \\
\hline $\begin{array}{l}\text { Cyclodextrins } \\
\text { (CDs) }\end{array}$ & RA-CD complexes & $\begin{array}{l}\text { - Water-soluble and photo-stable; } \\
\text { - } \quad \text { increased antioxidant capacity; }\end{array}$ & {$[108,109,111]$} \\
\hline Alginate beads & RA-loaded alginate beads & $\begin{array}{l}\text { - } \quad \text { Retention of a high amount of RA; } \\
\text { excellent inhibitors of } \\
\text { acetylcholinesterase. }\end{array}$ & [112-114] \\
\hline
\end{tabular}


Table 1. Cont

\begin{tabular}{|c|c|c|c|}
\hline Type of Carrier & Host-Guest System & Main Features & Refs. \\
\hline Gelatin & $\begin{array}{l}\text { Gelatin-based films } \\
\text { containing RA }\end{array}$ & $\begin{array}{l}\text { - } \quad \text { RA is covalently bond to the carrier; } \\
\text { good water resistance property, } \\
\text { strong mechanical properties and } \\
\text { excellent ultraviolet light } \\
\text { barrier ability; } \\
\text { effective antioxidant and } \\
\text { antibacterial activities. }\end{array}$ & [115] \\
\hline RA & $\begin{array}{l}\text { Crosslinked poly(RA) } \\
\text { particles }\end{array}$ & $\begin{array}{l}\text { Effective release of RA in acidic, } \\
\text { neutral and basic environments; } \\
\text { antioxidant activity } \\
\text { indistinguishable from RA; } \\
\text { poly(RA) particles are less cytotoxic } \\
\text { to mammalian cells than RA } \\
\text { monomer and show inhibition of } \\
\alpha \text {-glycosidase. }\end{array}$ & [92] \\
\hline $\begin{array}{l}\text { Polylactic-co-glycolic acid } \\
\text { (PLGA) and poly-lactic } \\
\text { acid (PLA) }\end{array}$ & $\begin{array}{l}\text { RA-loaded PLGA or PLA } \\
\text { microparticles }\end{array}$ & $\begin{array}{l}\text { - The encapsulation efficiency of RA } \\
\text { increased by co-encapsulation with } \\
\beta-C A \text { and } \alpha \text {-TOC. }\end{array}$ & [116] \\
\hline Polycaprolactone (PCL) & $\begin{array}{l}\text { RA-loaded PCL } \\
\text { microspheres }\end{array}$ & $\begin{array}{l}\text { Better long-term stability of RA in } \\
\text { cream formulations containing } \\
\text { RA-loaded PCL than with only RA }\end{array}$ & [93] \\
\hline $\begin{array}{l}\text { Poly (3-hydroxybutyrate- } \\
\text { co-3-hydroxyvalerate) } \\
\text { (PHBV) }\end{array}$ & $\begin{array}{l}\text { RA-loaded ultrathin } \\
\text { fibers of PHBV }\end{array}$ & $\begin{array}{l}\text { - Functional fibers were obtained by } \\
\text { electrospinning; } \\
\text { continuous films produced by } \\
\text { annealing of resultant electrospun } \\
\text { mats showed antimicrobial and } \\
\text { antioxidant activity in both open } \\
\text { and closed systems. }\end{array}$ & [117] \\
\hline Liposomes, ethosomes & $\begin{array}{l}\text { RA-loaded liposomes } \\
\text { and ethosomes }\end{array}$ & $\begin{array}{l}\text { - Used to increase the transdermal } \\
\text { penetration of RA }\end{array}$ & {$[118,120,121]$} \\
\hline $\begin{array}{l}\text { Solid lipid nanopoarticles } \\
\text { (SLNs) }\end{array}$ & RA-loaded SLNs & $\begin{array}{l}\text { - Used for oral nutraceutical } \\
\text { formulation; } \\
\text { Used for therapeutic approach for } \\
\text { neurodegenerative disorders. }\end{array}$ & {$[123,124]$} \\
\hline $\begin{array}{l}\text { Nanostructured lipid } \\
\text { carrier (NLC) }\end{array}$ & RA-loaded NLC & - Used for topical application. & [125] \\
\hline Nanoemulsions & $\begin{array}{l}\text { RA containing } \\
\text { nanoemulsions }\end{array}$ & $\begin{array}{l}\text { Used for nasally delivered } \\
\text { neuroprotective therapy when } \\
\text { associated to mucoadhesive } \\
\text { biopolymer; } \\
\text { - } \quad \text { used for topical application }\end{array}$ & {$[126,127]$} \\
\hline
\end{tabular}




\subsubsection{Bionanosystems Based on Inorganic Carriers}

Most examples of carriers for RA encapsulation or immobilization have involved polymerbased or lipid-based systems, while inorganic carriers are less investigated (Table 2). However, considering the possible application of RA as a natural antioxidant or antimicrobial additive for industries such as food packaging, cosmetics and pharmaceutical, bionanosystems made of inorganic nanoparticles and RA might have several advantages. It has been found that the high surface area and layered structure of nanoclays, as well as the hollow tubular structure of halloysite are ideal for promoting the absorption of essential oils (EOs) [128-130]. Furthermore, combining nanofillers with functional additives afford to host-guest systems that can be processed with a polymer matrix improving polymer performance due to the synergistic combination of physicochemical and biological properties of both phases.

The intercalation of bioactive compounds into inorganic layered materials, such as cationic and anionic clays, allows for host-guest systems that can be used as biocompatible carriers for drugs and other active chemicals. The 2D geometry of layered nanofillers is advantageous for self-assembly into organized layered structures of functional organic molecules, which are released in a controlled manner. Notably, nanoclays have been widely used as carriers of essential oils (EOs) and polyphenols for various applications such as food packaging and agricultural applications [131-133]. These hybrid systems act as a carrier to disperse hydrophobic molecules into hydrophilic matrices $[134,135]$ and represent an option to prepare aroma-controlled release systems for pest control [136]. Montmorillonite (MMT) is the most widely studied cationic clay. MMT has a layered structure where each layer consists of an octahedral sheet of alumina sandwiched between two tetrahedral sheets of silica. The layers are spaced from each other by a regular interlamellar space in which cations are located to compensate for the negative charge of the lamellae due to isomorphic substitution, and dur to these characteristics it is possible to insert organic molecules into the interlamellar space, generally by cation exchange, but also by adsorption. Some studies show that polyphenols can be intercalated into the interlayer spaces of MMT or adsorbed onto the external planar surfaces $[130,137,138]$. To the best of our knowledge, only two examples are described concerning the immobilization of RA on MMT. Giannakas et al. [131] investigated the immobilization of EOs from thyme, oregano, and basil into Na-MMT and organo-MMT. Primary components of these EOs are monoterpenoids and monoterpenes, but additional active compounds such as polyphenols, and among them eugenol, thymol, carvacrol, and RA, are also present. The immobilization of EOs on MMT was successful, and results demonstrated that in the case of Na-MMT the phenolic components of $\mathrm{EO}$ were immobilized on the external surface of clay layers via hydrogen bond with the $\mathrm{OH}$ groups, whereas in the case of organo-MMT they were intercalated as demonstrated by the increment of the interlayer space. Another interesting example of immobilization of RA into a layered silicate is that reported by Izadi et al. [139], which describes the intercalation by cation exchange of aqueous-based basil extract containing RA into Na-MMT for preparing a green inhibitive nanocarrier (G-MMT). Tannins, alkaloids, flavonoids, saponins, steroids, sterols, and phenols are indeed efficient corrosion inhibitors for protection of metals $[140,141]$ owing to heterocyclic rings, heteroatoms, and double/triple bonds. Therefore, G-MMT was here used in combination with a sol-gel silane coating to protect steel coupons against $3.5 \mathrm{wt} . \% \mathrm{NaCl}$ electrolyte. It was demonstrated a time-dependent release of the green inhibitor from the carrier and an efficient protective effect against steel corrosion which was five times higher than that of the additive-free hybrid silane coating. The protective effect was attributed at the precipitation of $\mathrm{Fe}^{2+} /$ basil extract chelates on the superficial active region [142]. In particular, it was found that the formation of chelates occurs precisely with RA and $\mathrm{Fe}^{2+}$. Possibly RA in neutral electrolytes is in the carboxylate anion form because its 1st dissociation constant (pKa1) is 2.92 [102], and the chelates are formed by interaction between RA and empty orbital of transition metal. The chelates can precipitate on the steel coupon surface, especially at active corrosion regions. In addition, the interaction between the -OH active groups present in the RA structure and $\mathrm{Fe}^{2+}$ cations are another possible mechanism for chelate formation. 
Halloysite (HNT) is a two-layered aluminosilicate clay similar to kaolin with the form of hollow tubes with an external diameter of about 50-80 nm, an internal diameter of 10-15 nm and a length of about $1000 \mathrm{~nm}$. HNT nanotubes can effectively encapsulate active agents in the hollow structure due to a high adsorption capacity that is higher than that observed for other clays, which results in a slower release rate of any active agent from HNT [143]. Films containing HNT as a carrier for rosemary essential oil [144] and peppermint oil [145] have been reported describing the controlled release of the active components such as RA.

Among the inorganic lamellar-structured reservoirs, the layered double hydroxides (LDHs), also called hydrotalcites, deserve special attention because they are very effective in adsorbing and intercalating organic molecules, as well as in releasing them in a controlled manner, and protecting them from external agents. LDHs are anionic clays consisting of positively charged and pillared hydroxide lamellae balanced by hydrated anions intercalated between the layers. The interlayer anions can be easily exchanged to produce intercalated systems containing both inorganic and organic anions, which are firmly anchored by ionic bond [146]. LDHs have been used as nanocarriers of antioxidants such as carnosine acid, gallic acid, vanillic acid, ferulic acid, caffeic acid, and many others [147-149]. The intercalation between the layers not only protects these molecules from oxidation and thermal degradation, but it also reduces the effects of migration, and shows release behavior suitable for their use in controlled delivery systems. Furthermore, the organo-modification of LDH improves the compatibility with polymer matrices, thus making LDHs particularly interesting and versatile as additives for polymer composites. Modification of LDH with salicylate anions [150] and benzoic acid derivatives [151-153], known for antibacterial properties, is described in the literature. Additionally, these functional fillers have successfully dispersed in various polymer matrices, demonstrating that the functional host-guest systems slowly release their contents to maintain antimicrobial agent concentrations at desired levels over a long period of time. Interestingly, polyphenol extracted by olive mill wastewater, which are natural antioxidants and in some cases also antimicrobials, have been confined into the host structure of a $\mathrm{ZnAl}-\mathrm{LDH}$ and employed as an integrative filler for the preparation of poly(butylene succinate) (PBS) composites by in situ polymerization [154]. The antibacterial properties were assessed against Staphylococcus aureus and Escherichia coli as representatives of potential agents of foodborne illnesses. Similarly, Sisti et al. [155] intercalated olive mill wastewater into $\mathrm{ZnAl}-\mathrm{LDH}$ with the aim of enhancing the durability of polypropylene and PBS melt-blended composites. More recently a few of us reported the preparation of antibacterial host guest systems by intercalation of mono-deprotonated rosmarinic and salycilic acid into a nitrate-intercalated MgAl LDH via anion exchange [156]. The hybrid systems (i.e., rosmarinate-LDH and salicylate-LDH) were successfully dispersed into linear low-density polyethylene (LDPE) (Figure 9), demonstrating that the nanocomposite material containing rosmarinate-LDH was selective and strongly inhibitory toward Staphylococcus aureus. Additionally, the overall migration of rosmarinate from films immersed in $95 \%$ ethanol solution was followed by fluorescence spectroscopy showing a controlled release of the active compound. Furthermore, a significant effect of stabilization of LDPE thermal-oxidation degradation was observed for nanocomposites due to the antioxidant power of RA. These results encourage future studies by using RA extracted from residual biomasses to improve the economic feasibility of the process. Moreover, fluorescence emission of the materials is an interesting feature that could be exploited for traceability in packaging applications. 


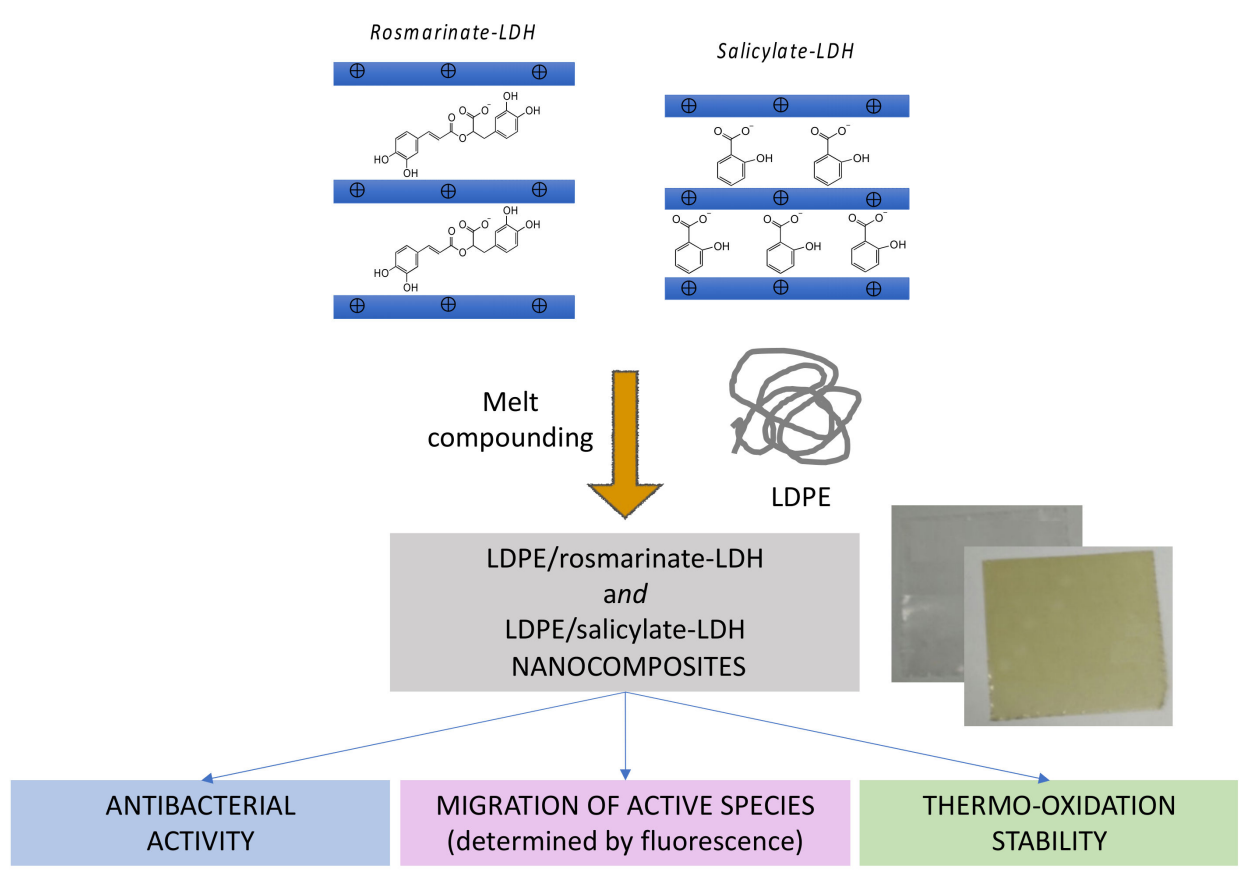

Figure 9. Rosmarinate-LDH and salicylate-LDH, their dispersion into LDPE, and main properties of LDPE/rosmarinate-LDH and LDPE/salicylate-LDH nanocomposites.

Table 2. Encapsulation of RA in in organic nano and microsystems.

\begin{tabular}{|c|c|c|c|}
\hline Type of Carrier & Host-Guest System & Main Features & Refs. \\
\hline Montmorillonite (MMT) & $\begin{array}{l}\text { Intercalated and adsorbed } \\
\text { RA-MMT }\end{array}$ & $\begin{array}{l}\text { - RA contained in thyme, oregano and } \\
\text { basil EOs is immobilized on the } \\
\text { external surface of Na-MMT and } \\
\text { intercalated in organo-MMT; } \\
\text { RA-MMT is a green inhibitive } \\
\text { nanocarrier releasing RA and protecting } \\
\text { against steel corrosion due to the } \\
\text { precipitation of } \mathrm{Fe}^{2+/} \mathrm{RA} \text { chelates. }\end{array}$ & {$[131,139]$} \\
\hline $\begin{array}{c}\text { Halloysite } \\
\text { nanotubes (HNTs) }\end{array}$ & Encapsulated RA-HNTs & $\begin{array}{l}\text { - } \quad \text { RA is gradually released from films } \\
\text { containing rosemary EO-HNT }\end{array}$ & [144] \\
\hline $\begin{array}{l}\text { Layered double } \\
\text { hydroxides (LDHs) }\end{array}$ & Intercalated RA-LDH & $\begin{array}{l}\text { - Mono-deprotonated RA is intercalated } \\
\text { in LDH; } \\
\text { LDPE nanocomposites containing } \\
\text { RA-LDH show antibacterial activity; } \\
\text { LDPE nanocomposites containing } \\
\text { RA-LDH are stabilized towards } \\
\text { thermal-oxidation degradation; } \\
\text { LDPE nanocomposites containing } \\
\text { RA-LDH are fluorescent. }\end{array}$ & [156] \\
\hline $\begin{array}{c}\text { Silica } \\
\text { nanoparticles }\end{array}$ & $\begin{array}{l}\text { Covalently grafted or } \\
\text { adsorbed RA silica } \\
\text { nanoparticles }\end{array}$ & $\begin{array}{l}\text { - The system has antioxidant activity; } \\
\text { - The system can be used as carrier for } \\
\text { the delivery of active compounds. }\end{array}$ & [157-159] \\
\hline $\begin{array}{l}\text { Metal organic framework } \\
\text { (MOF) }\end{array}$ & $\begin{array}{c}\text { RA-loaded } \\
\text { UiO-66-NH2@N-CNDs } \\
\text { nanoparticles }\end{array}$ & $\begin{array}{l}\text { - Bionanosystem with possible } \\
\text { antitumoral activity. }\end{array}$ & [160] \\
\hline
\end{tabular}


Porous silica nanoparticles, with interesting applications in pharmaceutical formulations, in biomedical devices and in early diagnosis of diseases, have also been proposed as alternative nanocarriers of bioactive molecules. However, despite their excellent properties, such as biocompatibility, high specific surface area and versatility on its surface functionalization, some issues related to their toxicity in some tissues, industrial scaling, and optimization in specific drug delivery, still remain. To overcome some of these challenges, the development of systems called nanoantioxidants is an interesting approach. These systems are nanoparticles with intrinsic antioxidant activity and / or antioxidant-functionalized nanoparticles that, besides having antioxidant activity, are more biocompatible, and have applications as pharmaceutical excipients, in food packaging or as pharmaceutical carriers. Many antioxidants are used to prepare these systems [157] and among these, also RA has been used. In particular, RA has been covalently immobilized onto the surface of mesoporous silica nanoparticles that have been previously modified with ammine group (Figure 10) [158]. The antioxidant activity of this system was proved by the DPPH test. Moreover, this nanoantioxidant has been used as a carrier for the delivery of morin $(3,5,7,20,40$-pentahydroxyflavone) $(\mathrm{MH})$, a flavonoid commonly present in various fruits and vegetables of the Moraceae family, with remarkable antioxidant, anti-inflammatory, neuroprotective, and anti-cancer activity. Despite its interesting properties, it has very low oral bioavailability. Its immobilization into RA/modified mesoporous silica nanoparticles has allowed its delivery and release at an intestinal level.

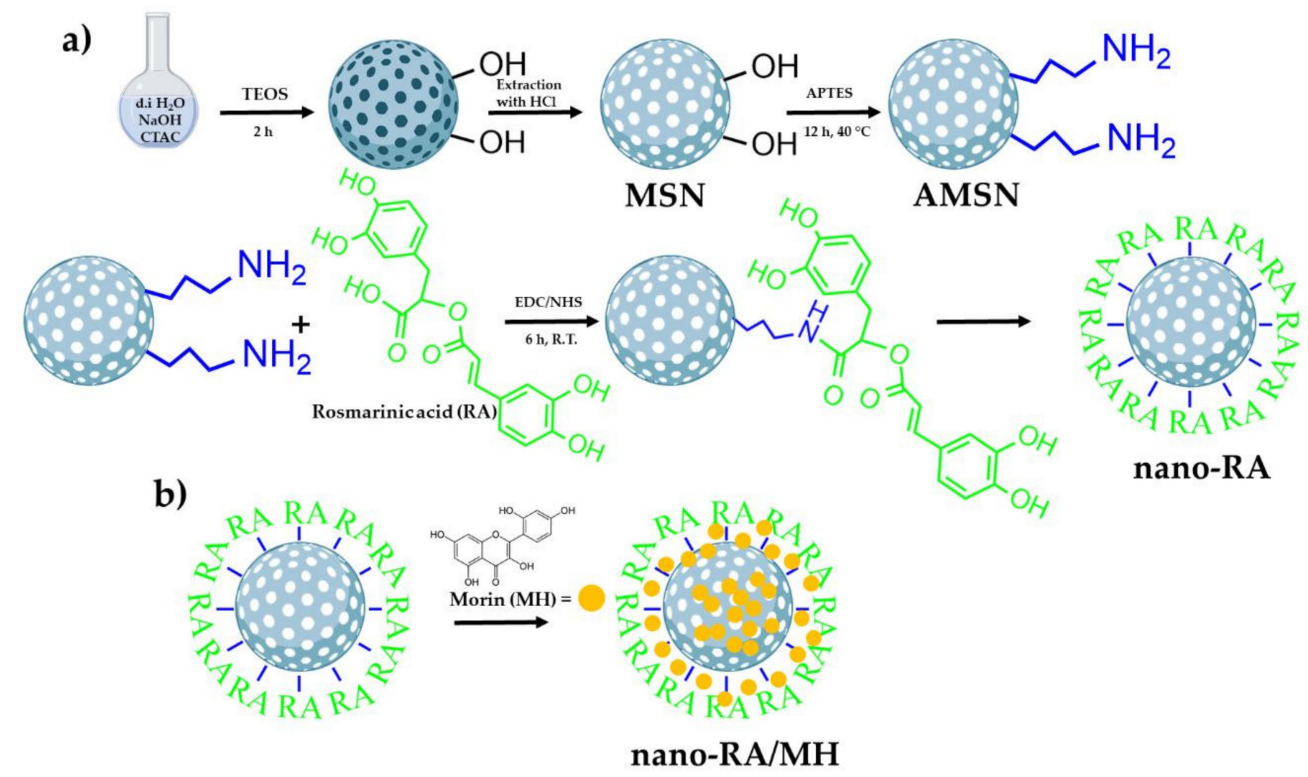

Figure 10. Schematic representation of the preparation of morin-loaded nanoantioxidants (nano$\mathrm{RA} / \mathrm{MH}$ ). (a) Schematic path to obtain the antioxidant nanocarrier (nano-RA) and (b) schematic representation of the loading of morin in the nano-RA (nano-RA/MH) (adapted from Arriagada et al. [158], copyright $2020 \mathrm{MDPI})$.

Mesoporous silica nanoparticles modified with four kinds of ammino groups were also used as solid phase adsorbents for RA or RA mixed with other aromatic acids [159]. The authors stated that in dynamic conditions, RA is adsorbed better than other aromatic acids and is better retained in the silica nanoparticles modified with 3-[(trimethoxysilyl)propyl] diethylenetriamine. The adsorption amount of RA and of other acids depends on different effects such as adsorption strategies, adsorption modes, structure-activity relationship, steric hindrance, and interaction forces.

Another nanoparticle system where RA has been loaded is the metal organic framework (MOF) made of zirconium and amino terephthalic acid (UiO-66-NH2) [160]. The authors first modified the UiO-66-NH2 with fluorescent $\mathrm{N}$-doped carbon nanodots (N-CNDs), that are very effective in photo-thermal therapy, then loaded these nanoparticles 
with RA. An amount of 7\% of RA was loaded in UiO-66-NH2@N-CNDs nanoparticles showing a sustained release over a period of $50 \mathrm{~h}$. This system can be used for drug delivery and simultaneously for fluorescence imagining. Furthermore, the RA addition to UiO-66NH2@N-CNDs nanoparticles further increases their activity because RA beside being a strong antioxidant also has antitumoral activity. Interestingly, methylthiazolyl tetrazolium assay showed that when RA is loaded onto the nanocarrier, the required amount of active molecules are significantly reduced because this nanocarrier can absorb UV irradiation by $\mathrm{N}$-doped carbon nanodots and act synergically with the released RA.

Finally, an unusual application of RA that exploits its antioxidant and reducing ability is in the preparation, stabilization, and surface modification of gold and silver nanoparticles from the corresponding salts [161]. The authors stated that by using RA, no external stabilizer is necessary and hypothesized the use of the so-formed nanoparticles in different applications, including biomedical imaging, gene and drug delivery, disease detection and therapy.

\subsection{Bionanosystems for Ulvan}

The production of bionanosystems based on ulvan must consider the specific properties of this polymer in water solutions. Negative groups can be present on the macromolecular structure due to the presence of carboxylate and sulphate groups. In good agreement, Paradossi et al. [162] noticed an aggregating tendency of ulvan in dilute aqueous solutions in the presence of $0.1 \mathrm{M} \mathrm{NaCl}$. In addition, in the presence of divalent cations, such as $\mathrm{Ca}^{2+}$, ulvan has gelling properties in a $\mathrm{pH}$ range of 7.5 to 8.0 [163]. In addition, the negative groups can be exploited to prepare specific nanostructured systems, with the aim of improving specific functional properties of ulvan or combining it with other functional agents.

For example, ulvan was used to produce antimicrobial biofilms of silver for food packaging [164]. In the food industry, nisin is a biopreservative with antimicrobial properties against Gram-positive bacteria and the nisin-loaded ulvan particles were more stable and thus, ulvan was used as a carrier for the small nisin molecule [165]. The latter has the tendency of generating positive ions in water solution due to the presence of basic $-\mathrm{NH}-$ moieties, hence the regulation of $\mathrm{pH}$ during the preparation of the particles was pivotal.

Ulvan (obtained from $U$. lactuca) was modified as a carrier system to deliver waterinsoluble metabolites. The produced nanogels were based on ulvan acetate self-organized in aqueous solution, increasing the solubility of the yellow pigment curcumin extracted from Curcuma longa rhizomes [166]. Curcumin is hydrophobic in nature, so it has poor solubility in water or hydrophilic solutions, but it is an important natural polyphenol with notably anti-inflammatory and other biological properties [167]. It contains -OH groups that may develop interactions with similar groups in the polysaccharide. The acetylated polysaccharide ulvan was efficiently converted to nanogels to deliver curcumin in aqueous medium [166].

Drug delivery was also exploited to form nanostructures combining the anionic characteristic of ulvan (from $U$. rigida) and the lysozyme, the ubiquitous positive charged enzyme at neutral $\mathrm{pH}$. Synergistic properties were verified most probably attributed to the nanoscale and the complexes displayed higher antibacterial activity against Staphylococcus aureus when compared with the enzyme or the polymer alone [67].

Application in the synthesis of hydrogels and bioactive membranes for biomedical application was also demonstrated [72]. Exploiting the tissue engineered bioactive biorenewable scaffolds, complexes of ulvan and chitosan were designed, i.e., mixtures of positively and negatively charged polyelectrolytes blended at the molecular level [168]. Polyelectrolyte membranes are new generation of biomaterials composed of the natural polymers and can include ulvan as well as ulvan/chitosan membranes to stimulate the attachment and proliferation of specialized cells such as osteoblasts [168]. These matrices are similar to green avenues for scaffold and membrane developments and the future for macroalgae with high impact in biomedical applications. 
Although many experiments have been conducted on formulations involving chitin/ chitosan nanoparticles with the combination of RA, few studies proposed the incorporation of ulvan in preparations containing a matrix of chitin or chitosan. In the preparations it is important to mention the detailed structural analysis of chitosan since defined chitosan are important to their bioactivities [169] and the same for ulvan, resulting in the second generation of highly defined active molecules.

Nanoparticles of chitosan-ulvan (from U. ohnoi) were obtained and presented immunostimulant activity inducing an oxidative burst in fish macrophage [170]. The nanoparticles could be potentially used as nanocarries in feed additives or vaccine vehicles in aquaculture considering that the high molecular weight ulvan polymer was more active and the low molecular weight loose the immune-stimulatory activity in vitro [170].

Barros et al. [171] reported that modified carboxymetylated chitosan and ulvan (obtained from $U$. lactuca) were combined to generate non-cytotoxic bone cements. Furthermore, a biocompatible soft material consisting of an ulvan-chitosan complex was developed and the ulvan aqueous solution was added chitosan solution to form a hydrogel [86].

\section{Applications}

As evidenced in Section 1, RA, extracted from different plants, shows many interesting functional properties that were tested and listed by several authors [33,91]. The interesting properties of RA are summarized in Figure 11.

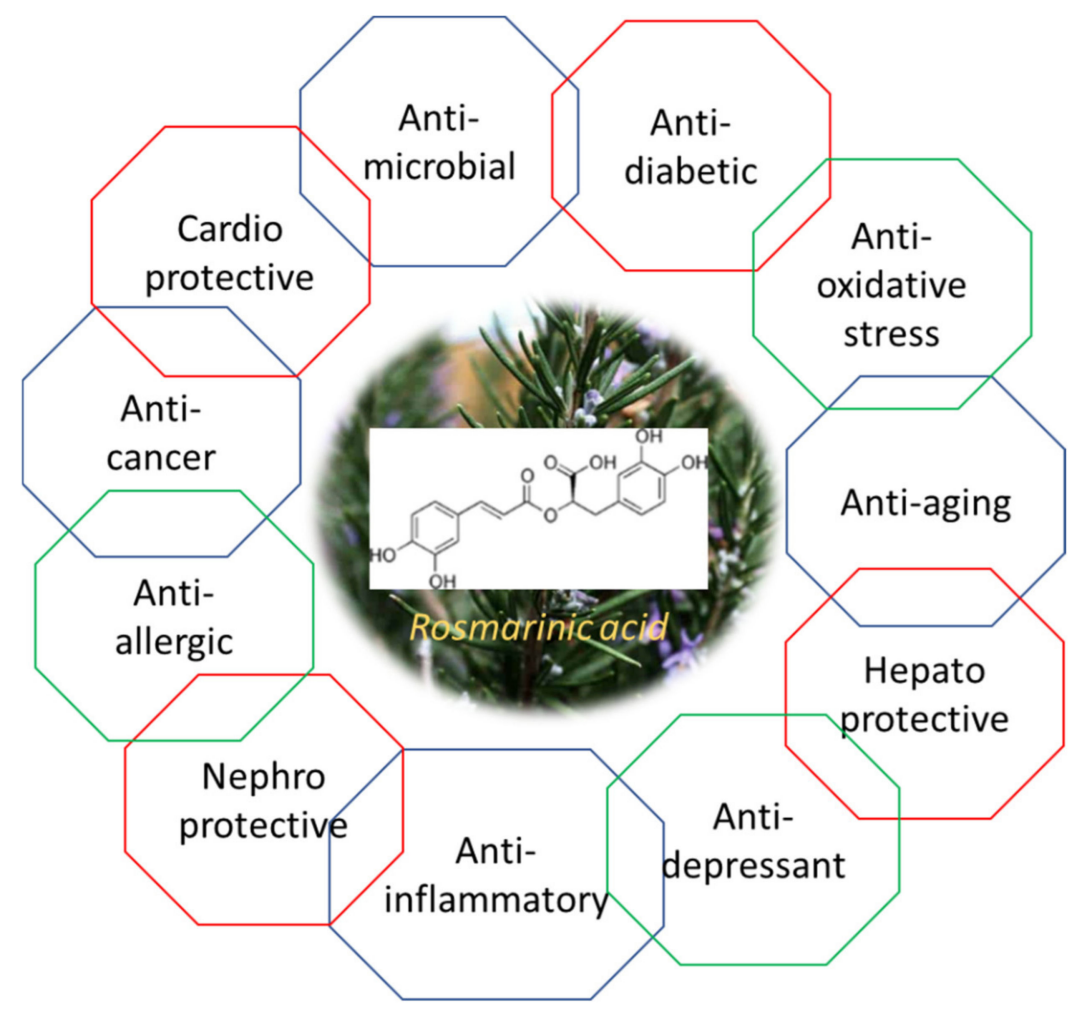

Figure 11. Exploitable properties of RA.

Thanks to the preparation of different organic or inorganic carriers (Section 4.1) RA can be incorporated in bionanosystems, that represent an advantageous more stable and effective form of RA. Bionanosystems can be available as solid powders or as liquid systems if liquid nanoparticles are available in suspensions or emulsions, such as in the case of gel microcapsules or liposomes. 
Coatings containing RA could allow this functional molecule to be deposited onto surfaces to have specific anti-microbial properties. For instance, RA was suspended in acidic water solution with chitosan to prepare a coating that helped in increasing the shelf life of fish fillets [172] thanks to the anti-microbial properties of both chitosan and RA.

Moreover nasal $[124,173,174]$ and ocular $[175,176]$ liquid treatments were prepared containing RA.

Despite gaps in the literature regarding this subject, the incorporation of RA bionanosystems in liquid coatings to treat plastic, metal or ceramic surfaces to widen the use of RA in several solid consumer goods. Would certainly be possible. In addition, the use of electrospray was found to be useful in producing RA incorporating biopolymeric particles by Vatankhan et al. [177]. Electrospray is a technique very useful not only in the production of solid powder, but also to anchor polysaccharides particles consisting of chitin nanofibrils on several surfaces, especially tissues, as demonstrated by Azimi et al. [178,179]. Hence, the use of this technique could be extended to RA bionanosystems incorporated in a biopolymer matrix as a methodology to modify biopolymers substrates. Another interesting technique that can be applied to incorporate powders in non-woven tissues is dry powder impregnation, which has been thoroughly investigated in the biomedical and cosmetic field [9]. However, the potentialities of the latter techniques for applying RA on several substrates to obtain products for personal care, sanitary and cosmetic products would require more research.

The incorporation of RA in hydrosuspendable biopolymers can easily be realized through casting techniques under water evaporation, as proposed by Ge et al. [115], who prepared gelatin films containing RA. In any case, polymers efficient in packaging are thermoplastic hydrorepellent. The incorporation of RA in such thermoplastic bulk material requires further investigation into the correct methodologies for melt blending and extrusion. Recently, Coiai et al. [156] have studied the dispersion of RA and salicylic acid (SA) binanosystems based on different LDHs in LDPE, a polymer widely used in packaging applications. The good dispersion results, the final anti-microbial properties towards Staphylococcus aureus and the controlled release kinetic of the obtained films evidenced that these bionanosystems are good intermediates for obtaining interesting functional biomaterials that could be exploited in packaging and other applications.

In recent years, significant improvements and developments have been made in algaebased polysaccharides with increased focus on ulvan. Demand for renewable resources and a unique polymer matrix is increasing and innovative approaches are required in modern formulations, for aquaculture, food packaging or biomedical applications such as drug delivery, wound dressings, tissue engineering and antimicrobial coatings. Marine sulfated polymers such as ulvan (Figure 12) represent a potential inexpensive resource for these applications and the large number of articles published on this topic in the last two to three years highlights its great importance $[67,72]$.

Suitable bionanosystems incorporating ulvan can be available as solid powders, liquid suspensions or gels, as described in Section 4.2.

In order to prepare functional materials suitable for producing final products production, it is reasonable to consider the aggregation state of the addressed final products. Moreover, techniques that allow a suitable amount of bionanosystems to be deposited on the material should be selected.

Certainly, bionanocomposites should be easily dispersible in the final products. Compatibilizers, as well as specific techniques to graft them on solid surfaces, can allow more effective results, including good homogeneity and addressed properties. 

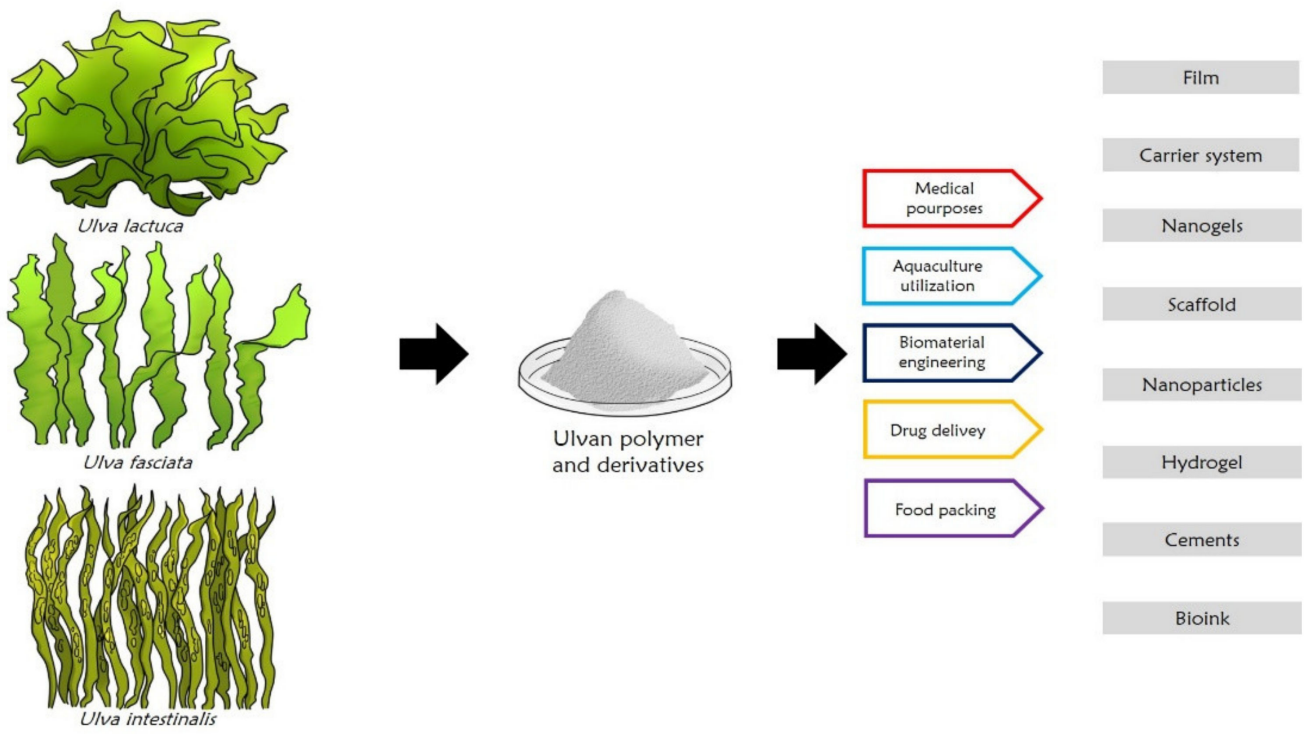

Figure 12. Schematic representation of the ulvan sources leading to different applications sectors and functional biomaterials.

In the case of ulvan, possible grafting with polymers was studied by Morelli et al. [180]. They grafted a few acrylic monomers onto ulvan through esterification reaction between the hydroxyl groups of ulvan and acryloylchloride. At this point, ulvan was transformed in a macromonomer that could be polymerized with poly(N-isopropylacrylamide). The authors obtained thermosensitive gels quite interesting for biomedical applications. However, the methodology they followed is quite general and may allow ulvan to be grafted on the polymers synthesizable by polyadditions. Thus, this is a route to produce several compatibilizers that may allow ulvan to be incorporated into several polymeric materials, both for liquid (varnishes, coatings, etc ... ) or solid applications (tissues, films, etc ... ).

In general, Morelli et al. [181], working on cosmetic applications of ulvan, suggested that the dispersion of ulvan in oil in water emulsions, typical of cosmetic products such as body creams, can be facilitated using specific techniques such as ultrasounds.

Interestingly, Gadenne et al. [182] grafted ulvan on metal surfaces. Ulvan was covalently immobilized on titanium surfaces which had been previously functionalized by self-assembled monolayers of aminoundecyltrimethoxysilane (AUTMS). This latter worked as a primer coating on the metal. Anti-adhesive properties of titanium implants for biomedical applications were improved thanks to the surface grafting of ulvan. On the other hand, inhibition of marine fouling on surfaces has been a critical issue in marine industries, as severe adhesion of marine foulants on the surface of marine vessels eventually leads to increased fuel consumption. Marine fouling resistance was significantly enhanced by ulvan. This aspect was also investigated by Jeong et al. [183]. To achieve this, a solid titanium surface was treated with plasma to insert hydroxyl groups by immersion into an ethanol solution of (3-aminopropyl) triethoxysilane (APTES). In situ polycondensation of APTES followed by covalent bond formation with ulvan allowed obtaining monolayer coatings that reduced of $60 \%$ the adhesion of diatom on the surface with respect to not-treated surfaces.

Membranes based on ulvan suitable for wound dressing applications were developed using a diepoxide (1,4-butanediol diglycidyl ether) cross-linking agent by Alves et al. [184]. In biomedical applications, and specifically in wound care, the use of ulvan hydrogel is also very promising, as recently evidenced by Sulastri et al. [185] in their review. The authors evidenced the necessity of performing further research on ulvan hydrogel applications and in vivo studies to facilitate a wider use of this material. 


\section{Conclusions}

This study discussed the sources and the extraction methodologies for obtaining rosmarinic acid (RA) and ulvan, starting with its sources, continuing to discuss its extraction methodologies, bionanosystems and its production, before analyzing its final applications (Figure 1). The resulting evidence demonstrated the high potentialities of both rosmarinic acid (RA) and ulvan as useful functional agents in several applications, ranging from biomedical, pharmacologic, cosmetic, and food packaging, as well as personal care and coatings.

RA is a small molecule that can be obtained by many terrestrial plants; hence its production could be increased considering agricultural products and their possible discards and waste. Several extractions methodologies were, up to now, studied that demonstrated the possibility of obtaining RA from several sources with a high yield and desired purity, despite the fact that its production is not yet performed with mature industrial technologies.

Ulvan is highly available from marine sources and its extraction was also investigated by several authors, but, despite its very interesting potentialities, industrial plants able to produce it in high amounts are not yet available, and this constitutes a current limitation to the wide use of this biopolymer.

The production of bionanosystems is fundamental for RA and can be incorporated in organic or inorganic substrates, granting high stability and a release control of the functional molecules during its use, thus enhancing its functional properties thanks to the exploitation of nanotechnology. Ulvan can be used as a carrier, or combined with molecules or biopolymer-like chitin derivatives.

Both RA and ulvan can develop negative charges which are able to determine their capacity to form bionanosystems or hybrid functional materials through nano-assembly by their combination with inorganic or organic systems, characterized by positive charges such as LDH or chitosan. This interesting behavior can certainly allow their use in the production of several functional biomaterials and in biobased products with high performances in a wide range of industrial sectors. The anti-microbial properties shown by both RA and ulvan, combined with their environmentally friendly feature, could be exploited in several products, considering also the COVID-19 pandemic that has currently enhanced this general necessity, thus combining the health and environmental needs of green-minded consumers.

Author Contributions: Conceptualization, S.C., L.P. and M.-B.C.; writing-original draft preparation, S.C., R.P., F.C., B.C. and L.P.; writing-review and editing, M.-B.C., F.C., E.B. and A.L. All authors have read and agreed to the published version of the manuscript.

Funding: This research received no external funding.

Institutional Review Board Statement: Not applicable.

Informed Consent Statement: Not applicable.

Data Availability Statement: Not applicable.

Acknowledgments: We thank Marion Cordeiro Langner for the design of the macroalgae and polymer (Figure 12). Francesca Ceron of University of Pisa, is acknowledged for the kind support related to information regarding the bioeconomy contest.

Conflicts of Interest: The authors declare no conflict of interest.

\section{References}

1. Grainger, A.; Smith, G. The role of low carbon and high carbon materials in carbon neutrality science and carbon economics. Curr. Opin. Environ. Sustain. 2021, 49, 164-189. [CrossRef]

2. Pittau, F.; Krause, F.; Lumia, G.; Habert, G. Fast-growing bio-based materials as an opportunity for storing carbon in exterior walls. Build. Environ. 2018, 129, 117-129. [CrossRef]

3. Briassoulis, D.; Pikasi, A.; Hiskakis, M. Organic recycling of post-consumer /industrial bio-based plastics through industrial aerobic composting and anaerobic digestion-Techno-economic sustainability criteria and indicators. Polym. Degr. Stab. 2021, 190, 109642. [CrossRef]

4. Coltelli, M.-B.; Danti, S. Biobased materials for skin-contact products promoted by POLYBIOSKIN project. J. Funct. Biomater. 2020, 11, 77. [CrossRef] 
5. Coltelli, M.-B.; Danti, S.; Trombi, L.; Morganti, P.; Donnarumma, G.; Baroni, A.; Fusco, A.; Lazzeri, A. Preparation of innovative skin compatible films to release polysaccharides for biobased beauty masks. Cosmetics 2018, 5, 70. [CrossRef]

6. Orlando, I.; Basnett, P.; Nigmatullin, R.; Wang, W.; Knowles, J.C.; Roy, I. Chemical modification of bacterial cellulose for the development of an antibacterial wound dressing. Front. Bioeng. Biotechnol. 2020, 24, 557885. [CrossRef]

7. Khattak, S.; Wahid, F.; Liu, L.P.; Jia, S.R.; Chu, L.Q.; Xie, Y.Y.; Li, Z.X.; Zong, C. Applications of cellulose and chitin/chitosan derivatives and composites as antibacterial materials: Current state and perspectives. Appl. Microbiol. Biotechnol. 2019, 103, 1989-2006. [CrossRef]

8. Coltelli, M.-B.; Danti, S.; De Clerck, K.; Lazzeri, A.; Morganti, P. Pullulan for advanced sustainable body- and skin-contact applications. J. Funct. Biomater. 2020, 11, 20. [CrossRef]

9. Teno, J.; Pardo-Figuerez, M.; Hummel, N.; Bonin, V.; Fusco, A.; Ricci, C.; Donnarumma, G.; Coltelli, M.-B.; Danti, S.; Lagaron, J.M. Preliminary studies on an innovative bioactive skin soluble beauty mask made by combining electrospinning and dry powder impregnation. Cosmetics 2020, 7, 96. [CrossRef]

10. Adlhart, C.; Verran, J.; Azevedo, N.F.; Olmez, H.; Keinänen-Toivola, M.M.; Gouveia, I.; Melo, L.F.; Crijns, F. Surface modifications for antimicrobial effects in the healthcare setting: A critical overview. J. Hosp. Infect. 2018, 99, 239-249. [CrossRef]

11. Massironi, A.; Morelli, A.; Puppi, D.; Chiellini, F. Renewable polysaccharides micro/nanostructures for food and cosmetic applications. Molecules 2020, 25, 4886. [CrossRef]

12. Alves, A.; Sousa, E.; Kijjoa, A.; Pinto, M. Marine-derived compounds with potential use as cosmeceuticals and nutricosmetics. Molecules 2020, 25, 2536. [CrossRef]

13. Faccio, G. Plant complexity and cosmetic innovation. iScience 2020, 23, 101358. [CrossRef] [PubMed]

14. Osorio, L.L.D.R.; Flórez-López, E.; Grande-Tovar, C.D. The potential of selected agri-food loss and waste to contribute to a circular economy: Applications in the food, cosmetic and pharmaceutical industries. Molecules 2021, 26, 515. [CrossRef]

15. Casanova, F.; Santos, L. Encapsulation of cosmetic active ingredients for topical application-A review. J. Microencapsul. 2016, 33, 1-17. [CrossRef]

16. Tardy, B.L.; Mattos, B.D.; Otoni, B.G.; Beaumont, M.; Majoinen, J.; Kämäräinen, T.; Rojas, O.J. Deconstruction and Reassembly of Renewable Polymers and Biocolloids into Next Generation Structured Materials. Chem. Rev. 2021. [CrossRef]

17. Nagamune, T. Biomolecular engineering for nanobio/bionanotechnology. Nano Converg. 2017, 4, 9. [CrossRef]

18. Tran, T.T.V.; Truong, H.B.; Tran, N.H.V.; Quach, T.M.T.; Nguyen, T.N.; Bui, M.L.; Yuguchi, Y.; Thanh, T.T.T. Structure, conformation in aqueous solution and antimicrobial activity of ulvan extracted from green seaweed Ulva reticulata. Nat. Prod. Res. 2018, 32, 2291-2296. [CrossRef]

19. Alagawany, M.; Abd El-Hack, M.; Farag, M.; Gopi, M.; Karthik, K.; Malik, Y.; Dhama, K. Rosmarinic acid: Modes of action, medicinal values and health benefits. Anim. Health Res. Rev. 2017, 18, 167-176. [CrossRef] [PubMed]

20. Petersen, M.; Simmonds, M.S. Rosmarinic acid. Phytochemistry 2003, 62, 121-125. [CrossRef]

21. Halliwell, B. Are polyphenols antioxidants or pro-oxidants? What do we learn from cell culture and in vivo studies. Arch. Biochem. Biophys. 2008, 476, 107-112. [CrossRef]

22. Ravn, H.; Pedersen, M.F.; Andray, J.; Borum, C.; Anthoni, U.; Christophersen, C.; Nielsen, P.H. Seasonal variation and distribution of two phenolic compounds, rosmarinic acid and caffeic acid, in leaves and roots-rhizomes of eelgrass (Zostera marina L.). Ophelia 1994, 40, 51-61. [CrossRef]

23. Petersen, M. Rosmarinic acid: New aspects. Phytochem. Rev. 2013, 12, 207-227. [CrossRef]

24. Scarpati, M.L.; Oriente, G. Isolamento e costituzione dell'acido rosmarinico (dal rosmarinus off.). Ric. Sci. 1958, 28, $2329-2333$.

25. Petersen, M.; Haeusler, E.; Meinhard, J.; Karwatzki, B.; Gerlowski, C. The biosynthesis of rosmarinic acid in suspension cultures of Coleus blumei. Plant Cell Tissue Organ Cult. 1994, 38, 171-179. [CrossRef]

26. Petersen, M.; Abdullah, Y.; Benner, J.; Eberle, D.; Gehlen, K.; Hücherig, S.; Janiak, V.; Kim, K.H.; Sander, M.; Weitzel, C.; et al. Evolution of rosmarinic acid biosynthesis. Phytochemistry 2009, 70, 1663-1679. [CrossRef] [PubMed]

27. Barberini, S.; Savona, M.; Raffi, D.; Leonardi, M.; Pistelli, L.; Stochmal, A.; Vainstein, A.; Pistelli, L.; Ruffoni, B. Molecular cloning of SoHPPR encoding a hydroxyphenylpyruvate reductase, and its expression in cell suspension cultures of Salvia officinalis. Plant Cell Tissue Organ Cult. 2013, 114, 131-138. [CrossRef]

28. Wang, H.; Provan, G.J.; Helliwell, K. Determination of rosmarinic acid and caffeic acid in aromatic herbs by HPLC. Food Chem. 2004, 87, 307-311. [CrossRef]

29. Hippolyte, I.; Marin, B.; Baccou, J.C.; Jonard, R. Growth and rosmarinic acid production in cell suspension cultures of Salvia officinalis L. Plant Cell Rep. 1992, 11, 109-112. [CrossRef] [PubMed]

30. Tada, H.; Murakami, Y.; Omoto, T.; Shimomura, K.; Ishimaru, K. Rosmarinic acid and related phenolics in hairy root cultures of Ocimum basilicum. Phytochemistry 1996, 42, 431-434. [CrossRef]

31. Amoah, S.K.; Sandjo, L.P.; Kratz, J.M.; Biavatti, M.W. Rosmarinic acid-pharmaceutical and clinical aspects. Planta Med. 2016, 82, 388-406. [CrossRef] [PubMed]

32. Bulgakov, V.P.; Inyushkina, Y.V.; Fedoreyev, S.A. Rosmarinic acid and its derivatives: Biotechnology and applications. Crit. Rev. Biotechnol. 2012, 32, 203-217. [CrossRef]

33. Nadeem, M.; Imran, M.; Aslam Gondal, T.; Imran, A.; Shahbaz, M.; Muhammad Amir, R.; Martins, N. Therapeutic potential of rosmarinic acid: A comprehensive review. Appl. Sci. 2019, 9, 3139. [CrossRef]

34. Chockalingam, N.; Muruhan, S. Anti-inflammatory properties of rosmarinic acid-a review. Int. J. Res. Phar. Sci. 2021, 8, 656-662. 
35. Jin, B.R.; Chung, K.S.; Hwang, S.; Hwang, S.N.; Rhee, K.J.; Lee, M.; An, H.J. Rosmarinic acid represses colitis-associated colon cancer: A pivotal involvement of the TLR4-mediated NF-кB-STAT3 axis. Neoplasia 2021, 23, 561-573. [CrossRef] [PubMed]

36. Marketwatch. Available online: https://www.marketwatch.com/press-release/rosmarinic-acid-market-size-2021-developmentstrategy-major-manufacturers-industry-share-future-trends-growth-factor-with-covid-19-impact-till-2026-2021-07-01 (accessed on 28 August 2021).

37. Lahaye, M.; Axelos, M.A.V. Gelling properties of water-soluble polysaccharides from proliferating marine green seaweeds (Ulva spp.). Carbohydr. Polym. 1993, 22, 261-265. [CrossRef]

38. Lahaye, M.; Robic, A. Structure and funcional properties of ulvan, a polysaccharide from green seaweeds. Biomacromolecules 2007, 8, 1765-1774. [CrossRef]

39. Kirkendale, L.; Saunders, G.W.; Winberg, P. A molecular survey of Ulva (Chlorophyta) in temperate Australia reveals enhanced levels of cosmopolitanism. J. Phycol. 2013, 49, 69-81. [CrossRef]

40. Wichard, T.; Charrier, B.; Mineur, F.; Bothwell, J.H.; De Clerck, O.; Coates, J.C. The green seaweed Ulva: A model system to study morphogenesis. Front. Plant Sci. 2015, 6, 72. [CrossRef] [PubMed]

41. Alves, A.; Sousa, R.A.; Reis, R.L. A practical perspective on ulvan extracted from green algae. J. Appl. Phycol. 2013, 25, 407-424. [CrossRef]

42. Figueira, T.A.; Silva, A.J.R.; Enrich-Prast, A.; Yoneshigue-Valentin, Y.; Oliveira, V.P. Structural characterization of ulvan polysaccharide from cultivated and collected Ulva fasciata (Chlorophyta). Adv. Biosci. Biotechnol. 2020, 11, 206-216. [CrossRef]

43. Moreira, A.; Cruz, S.; Marques, R.; Cartaxana, P. The underexplored potential of green macroalgae in aquaculture. Rev. Aquac. 2021, 1-22. [CrossRef]

44. Robic, A.; Sassi, J.-F.; Dion, P.; Lerat, Y.; Lahaye, M. Seasonal variability of physicochemical and rheological properties of ulvan in two Ulva species (Chlorophyta) from the Brittany coast. J. Phycol. 2009, 45, 962-973. [CrossRef] [PubMed]

45. Jaulneau, V.; Lafite, C.; Corio-Costet, M.-F.; Stadnik, M.J.; Salamagne, S.; Briand, X.; Esquerré-Tugayé, M.-T.; Dumas, B. An Ulva armoricana extract protects plants against three powdery mildew pathogens. Eur. J. Plant Pathol. 2011, 131, 393-401. [CrossRef]

46. Lahaye, M. NMR spectroscopic characterisation of oligosaccharides from Ulva rigida ulvan samples (Ulvales, Chlorophyta) degraded by a lyase. Carbohydr. Res. 1998, 314, 1-12. [CrossRef]

47. U Pezoa-Conte, R.; Leyton, A.; Baccini, A.; Ravanal, M.C.; Mäki-Arvela, P.; Grénman, H.; Xu, C.; Willför, S.; Lienqueo, M.E.; Mikkola, J.-P. Aqueous extraction of the sulfated polysaccharide ulvan from the green alga Ulva rigida-kinetics and modeling. Bioenerg. Res. 2017, 10, 915-928. [CrossRef]

48. Chi, Y.; Li, H.; Wang, P.; Du, C.; Ye, H.; Zuo, S.; Guan, H.; Wang, P. Structural characterization of ulvan extracted from Ulva clathrata assisted by an ulvan lyase. Carbohydr. Polym. 2020, 229, 115497. [CrossRef]

49. Paulert, R.; Brunel, F.; Melcher, R.L.J.; Cord-Landwehr, S.; Niehues, A.; Mormann, N.; Moerschbacher, B.M. The non-sulfated ulvanobiuronic acid of ulvans is the smallest active unit able to induce an oxidative burst in dicot cells. Carbohydr. Polym. 2021, 270, 118338. [CrossRef]

50. De Freitas, M.B.; Ferreira, L.G.; Hawerroth, C.; Duarte, M.E.R.; Noseda, M.D.; Stadnik, M.J. Ulvans induce resistance against plant pathogenic fungi independently of their sulfation degree. Carbohydr. Polym. 2015, 133, 384-390. [CrossRef]

51. Shao, P.; Chen, M.; Pei, Y.; Sun, P. In vitro antioxidant activities of different sulfated polysaccharides from chlorophytan seaweeds Ulva fasciata. International J. Biol. Macromol. 2013, 59, 295-300. [CrossRef]

52. Gajara, T.K.; Bhatt, H.; Khandelwal, A.; Vasu, V.T.; Reddy, C.R.K.; Lakshmi, D.S. A facile chemical cross-linking approach toward the fabrication of a sustainable porous ulvan scaffold. J. Bioact. Compat. Polym. 2020, 35, 301-313. [CrossRef]

53. Paulert, R.; Ascrizzi, R.; Malatesta, S.; Berni, P.; Noseda, M.D.; Carvalho, M.M.; Marchioni, I.; Pistelli, L.; Duarte, M.E.R.; Mariotti, L.; et al Ulva intestinalis extract acts as biostimulants and modulates metabolites and hormone balance in basil (Ocimum basilicum L.) and parsley (Petroselinum crispum L.). Plants 2021, 10, 1391. [CrossRef]

54. He, C.; Muramatsu, H.; Kato, S.-I.; Ohnishi, K. Characterization of an Alteromonas long-type ulvan lyase involved in the degradation of ulvan extracted from Ulva Ohnoi. Biosci. Biotechnol. Biochem. 2017, 81, 2145-2151. [CrossRef]

55. Coste, O.; Malta, E.J.; López, J.C.; Fernández-Díaz, C. Production of sulfated oligosaccharides from the seaweed Ulva sp. using a new ulvan-degrading enzymatic bacterial crude extract. Algal Res. 2015, 10, 224-231. [CrossRef]

56. Thanh, T.T.; Quach, T.M.T.; Nguyen, T.N.; Luong, D.V.; Bui, M.L.; Tran, T.T.V. Structure and cytotoxic activity of ulvan extracted from green seaweed Ulva lactuca. Int. J. Biol. Macromol. 2016, 93, 695-702. [CrossRef] [PubMed]

57. Zhao, C.; Lin, G.; Wu, D.; Liu, D.; You, L.; Högger, P.; Simal-Gandara, J.; Wang, M.; da Costa, J.G.M.; Marunaka, Y.; et al. The algal polysaccharide ulvan suppresses growth of hepatoma cells. Food Front. 2020, 1, 83-101. [CrossRef]

58. Wahlström, N.; Nylander, F.; Malmhäll-Bah, E.; Sjövold, K.; Edlund, U.; Westman, G.; Albers, E. Composition and structure of cell wall ulvans recovered from Ulva spp. along the Swedish west coast. Carbohydr. Polym. 2020, 233, 115852. [CrossRef] [PubMed]

59. Li, B.; Xu, H.; Wang, X.; Wan, Y.; Jiang, N.; Qi, H.; Liu, X. Antioxidant and antihyperlipidemic activities of high sulfate content purified polysaccharide from Ulva pertusa. Int. J. Biol. Macromol. 2020, 146, 756-762. [CrossRef]

60. Fort, A.; Lebrault, M.; Allaire, M.; Esteves-Ferreira, A.A.; McHale, M.; Lopez, F.; Farinãs-Franco, J.M.; Alseekh, S.; Fernie, A.R.; Sulpice, R. Extensive variations in diurnal growth patterns and metabolism among Ulva spp. strains. Plant Physiol. 2019, 180, 109-123. [CrossRef] 
61. Robic, A.; Gaillard, C.; Sassi, J.-F.; Lerat, Y.; Lahaye, M. Ultrastructure of ulvan: A polysaccharide from green seaweeds. Biopolymers 2009, 91, 652-664. [CrossRef]

62. Rydahl, M.G.; Kracun, S.K.; Fangel, J.U.; Michel, G.; Guillouzo, A.; Génicot, S.; Mravec, J.; Harholt, J.; Wilkens, C.; Motawia, M.S.; et al. Development of novel monoclonal antibodies against starch and ulvan-Implications for antibody production against polysaccharides with limited immunogenicity. Sci. Rep. 2017, 7, 9326. [CrossRef] [PubMed]

63. Kidgell, J.T.; Magnusson, M.; de Nys, R.; Glasson, C.R.K. Ulvan: A systematic review of extraction, composition and function. Algal. Res. 2019, 39, 101422. [CrossRef]

64. Lahaye, M.; Ray, B. Cell-wall polysaccharides from the marine green alga Ulva "rigida" (Ulvales, Chlorophyta) NMR analysis of ulvan oligosaccharides. Carbohydr. Res. 1996, 283, 161-173. [CrossRef]

65. Qi, H.; Sun, Y. Antioxidant activity of high sulfate content derivative of ulvan in hyperlipidemic rats. Int. J. Biol. Macromol. 2015, 76, 326-329. [CrossRef] [PubMed]

66. Robic, A.; Bertrand, D.; Sassi, J.-F.; Lerat, Y.; Lahaye, M. Determination of the chemical composition of ulvan, a cell wall polysaccharide from Ulva spp. (Ulvales, Chlorophyta) by FT-IR and chemometrics. J. Appl. Phycol. 2009, 21, 451-456. [CrossRef]

67. Tziveleka, L.; Ioannou, E.; Roussis, V. Ulvan, a bioactive marine sulphated polysaccharide as a key constituent of hybrid biomaterials: A review. Carbohydr. Polym. 2019, 218, 1-5. [CrossRef]

68. Robic, A.; Sassi, J.-F.; Lahaye, M. Impact of stabilization treatments of the green seaweed Ulva rotundata (Chlorophyta) on the extraction yield, the physico-chemical and rheological properties of ulvan. Carbohydr. Polym. 2008, 74, 344-352. [CrossRef]

69. Pengzhan, Y.; Ning, L.; Xiguang, L.; Gefei, Z.; Quanbin, Z.; Pengcheng, L. Antihyperlipidemic effects of diferente molecular weight sulfated polysaccharides from Ulva pertusa (Chlorophyta). Pharmacol. Res. 2003, 48, 543-549. [CrossRef]

70. Kidgell, J.T.; Glasson, C.R.K.; Magnusson, M.; Vamvounis, G.; Sims, I.A.; Carnachan, S.M.; Hinkley, S.F.R.; Lopata, A.L.; Nys, R.; Taki, A.C. The molecular weight of ulvan affects the in vitro inflammatory response of a murine macrophage. Int. J. Biol. Macromol. 2020, 150, 839-848. [CrossRef]

71. Zou, L.; Wang, L.; Zhang, J.; Cai, C.; He, P. Complete mitochondrial genome of Ulva linza, one of the causal species of green macroalgal blooms in Yellow Sea, China. Mitochondrial DNA B. Resour. 2016, 1, 31-33. [CrossRef]

72. Mo'o, F.R.C.; Wilar, G.; Devkota, H.P.; Wathoni, N. Ulvan, a polysaccharide from macroalga Ulva sp.: A review of chemistry, biological activities and potential for food and biomedical applications. Appl. Sci. 2020, 10, 5488. [CrossRef]

73. Jaulneau, V.; Lafitte, C.; Jacquet, C.; Fournier, S.; Salamagne, S.; Briand, X.; Esquerré-Tugayé, M.-T.; Dumas, B. Ulvan, a sulfated polysaccharide from green algae, activates plant immunity through the jasmonic acid signaling pathway. J. Biomed. Biotechnol. 2010, 2010, 525291. [CrossRef]

74. Paulert, R.; Ebbinghaus, D.; Urlass, C.; Moerschbacher, B.M. Priming of the oxidative burst in rice and wheat cells cultures by ulvan, a polysaccharide from green macroalgae, and enhanced resistance against powdery mildew in wheat and barley plants. Plant Pathol. 2010, 59, 634-642. [CrossRef]

75. Lakshmi, D.S.; Sankaranarayanan, S.; Gajaria, T.K.; Li, G.; Kujawski, W.; Kujawa, J.; Navia, R. A short review on the valorization of green seaweeds and ulvan: Feedstock for chemicals and biomaterials. Biomolecules 2020, 10, 991. [CrossRef] [PubMed]

76. Morelli, A.; Puppi, D.; Chiellini, F. Chapter 16- Perspectives on biomedical applications of Ulvan. In Seaweed Polysaccharides; Elsevier: Amsterdam, The Netherlands, 2017; pp. 305-330.

77. Ngo, Y.L.; Cher, H.L.; Lee, S.C. Review on rosmarinic acid extraction, fractionation and its anti-diabetic potential. Food Chem. Toxicol. 2018, 121, 687-700. [CrossRef] [PubMed]

78. Jacotet-Navarro, M.; Rombaut, N.; Fabiano-Tixier, A.S.; Danguien, M.; Bily, A.; Chemat, F. Ultrasound versus microwave as green processes for extraction of rosmarinic, carnosic and ursolic acids from rosemary. Ultrason. Sonochem. 2015, 27, 102-109. [CrossRef]

79. Chatterjee, A.; Tandon, S.; Ahmad, A. Comparative extraction and downstream processing techniques for quantitative analysis of rosmarinic acid in Rosmarinus officinalis. Asian J. Chem. 2014, 26, 4313. [CrossRef]

80. Herrero, M.; Plaza, M.; Cifuentes, A.; Ibáñez, E. Green processes for the extraction of bioactives from Rosemary: Chemical and functional characterization via ultraperformance liquid chromatography-tandem mass spectrometry and in-vitro assays. J. Chromatogr. A 2010, 1217, 2512-2520. [CrossRef] [PubMed]

81. Sik, B.; Lakatos, E.; Hanczné, E.L.; Kapcsándi, V.; Ajtony, Z. Conventional and nonconventional extraction techniques for optimal extraction processes of rosmarinic acid from six Lamiaceae plants as determined by HPLC-DAD measurement. J. Pharm. Biomed. Anal. 2020, 184, 113173. [CrossRef] [PubMed]

82. Caleja, C.; Barros, L.; Prieto, M.A.; Barreiro, M.F.; Oliveira, M.B.P.P.; Ferreira, I.C.F.R. Extraction of rosmarinic acid from Melissa officinalis L. by heat-, microwave-and ul-trasound-assisted extraction techniques: A comparative study through response surface analysis. Separ. Purif. Technol. 2017, 186, 297-308. [CrossRef]

83. Rodríguez-Rojo, S.; Visentin, A.; Maestri, D.; Cocero, M.J. Assisted extraction of rosemary antioxidants with green solvents. J. Food Engin. 2012, 109, 98-103. [CrossRef]

84. Ben Amor, C.; Jmel, M.A.; Chevallier, P.; Mantovani, D.; Smaali, I. Efficient extraction of a high molecular weight ulvan from stranded Ulva sp. biomass: Application on the active biomembrane synthesis. Biomass Convers. Biorefinery 2021. [CrossRef]

85. Reis, S.E.; Andrade, R.G.C.; Accardo, C.M.; Maia, L.F.; Oliveira, L.F.C.; Nader, H.B.; Aguiar, J.A.K.; Medeiros, V.P. Influence of sulfated polysaccharides from Ulva lactuca L. upon Xa and IIa coagulation factors and on venous blood clot formation. Algal Res. 2020, 45, 101750. [CrossRef] 
86. Kanno, K.; Akiyoshi, K.; Nakatsuka, T.; Watabe, Y.; Yukimura, S.; Ishihara, H.; Shin, N.; Kawasaki, Y.; Yano, D. Biocompatible Hydrogel from a Green Tide-Forming Chlorophyta. J. Sustain. Dev. 2012, 5, 38-45. [CrossRef]

87. Fang, Z.; Bhandari, B. Encapsulation of polyphenols-A review. Trends Food Sci. Technol. 2010, 21, 510-523. [CrossRef]

88. De Souza Simões, L.; Madalena, D.A.; Pinheiro, A.C.; Teixeira, J.A.; Vicente, A.A.; Ramos, Ó.L. Micro-and nano bio-based delivery systems for food applications: In vitro behavior. Adv. Colloid Interface Sci. 2017, 243, 23-45. [CrossRef] [PubMed]

89. Filipe, H.A.L.; Sousa, C.; Marques, J.T.; Vila-Viçosa, D.; de Granada-Flor, A.; Viana, A.S.; Santos, M.S.C.S.; Machuqueiro, M.; de Almeida, R.F.M. Differential targeting of membrane lipid domains by caffeic acid and its ester derivatives. Free Radic. Biol. Med. 2018, 115, 232-245. [CrossRef] [PubMed]

90. Marchev, A.S.; Vasileva, L.V.; Amirova, K.M.; Savova, M.S.; Koycheva, I.K.; Balcheva-Sivenova, Z.P.; Vasileva, S.M.; Georgiev, M.I. Rosmarinic acid-From bench to valuable applications in food industry. Trends Food Sci. Technol. 2021. [CrossRef]

91. Casanova, F.; Estevinho, B.N.; Santos, L. Preliminary studies of rosmarinic acid microencapsulation with chitosan and modified chitosan for topical delivery. Powder Technol. 2016, 297, 44-49. [CrossRef]

92. Sahiner, M.; Blake, D.; Fullerton, M.; Suner, S.; Sunol, A.; Sahiner, N. Enhancement of biocompatibility and carbohydrate absorption control potential of rosmarinic acid through crosslinking into microparticles. Int. J. Biol. Macromol. 2019, 137, 836-843. [CrossRef] [PubMed]

93. Kim, H.J.; Kim, T.H.; Kang, K.C.; Pyo, H.B.; Jeong, H.H. Microencapsulation of rosmarinic acid using polycaprolactone and various surfactants. Int. J. Cosmet. Sci. 2010, 32, 185-191. [CrossRef]

94. Munin, A.; Edwards-Lévy, F. Encapsulation of natural polyphenolic compounds; a review. Pharmaceutics 2011, 3, 793-829. [CrossRef] [PubMed]

95. Da Silva, S.B.; Amorim, M.; Fonte, P.; Madureira, R.; Ferreira, D.; Pintado, M.; Sarmento, B. Natural extracts into chitosan nanocarriers for rosmarinic acid drug delivery. Pharm. Biol. 2015, 53, 642-652. [CrossRef] [PubMed]

96. Estevinho, B.N.; Rocha, F.; Santos, L.; Alves, A. Microencapsulation with chitosan by spray drying for industry applicationsA review. Trends Food Sci. Technol. 2013, 31, 138-155. [CrossRef]

97. Belščak-Cvitanović, A.; Stojanović, R.; Manojlović, V.; Komes, D.; Cindrić, I.J.; Nedović, V.; Bugarski, B. Encapsulation of polyphenolic antioxidants from medicinal plant extracts in alginate-chitosan system enhanced with ascorbic acid by electrostatic extrusion. Food Res. Int. 2011, 44, 1094-1101. [CrossRef]

98. Da Silva, S.; Ferreira, D.; Pintado, M.; Sarmento, B. Chitosan-based nanoparticles for rosmarinic acid ocular delivery-in vitro tests. Int. J. Biol. Macromol. 2016, 84, 112-120. [CrossRef]

99. Madureira, A.R.; Pereira, A.; Castro, P.; Pintado, M. Production of antimicrobial chitosan nanoparticles against food pathogens. J. Food Eng. 2015, 167, 210-216. [CrossRef]

100. Liudvinaviciute, D.; Almonaityte, K.; Rutkaite, R.; Bendoraitiene, J.; Klimaviciute, R. Adsorption of rosmarinic acid from aqueous solution on chitosan powder. Int. J. Biol. Macromol. 2018, 118, 1013-1020. [CrossRef]

101. Liudvinaviciute, D.; Rutkaite, R.; Bendoraitiene, J.; Klimaviciute, R. Thermogravimetric analysis of caffeic and rosmarinic acid containing chitosan complexes. Carbohyd. Polym. 2019, 222, 115003. [CrossRef]

102. Al Danaf, N.; Abi Melhem, R.; Assaf, K.I.; Nau, W.M.; Patra, D. Photophysical properties of neutral and dissociated forms of rosmarinic acid. J. Lumin. 2016, 175, 50-56. [CrossRef]

103. Chhabra, P.; Chauhan, G.; Kumar, A. Augmented healing of full thickness chronic excision wound by rosmarinic acid loaded chitosan encapsulated graphene nanopockets. Drug Dev. Ind. Pharm. 2020, 46, 878-888. [CrossRef]

104. Dil, E.A.; Asfaram, A.; Goudarzi, A.; Zabihi, E.; Javadian, H. Biocompatible chitosan-zinc oxide nanocomposite based dispersive micro-solid phase extraction coupled with HPLC-UV for the determination of rosmarinic acid in the extracts of medical plants and water sample. Int. J. Biol. Macromol. 2020, 54, 528-537.

105. Pinho, E.; Grootveld, M.; Soares, G.; Henriques, M. Cyclodextrins as encapsulation agents for plant bioactive compounds. Carbohyd. Polym. 2014, 101, 121-135. [CrossRef]

106. Cai, R.; Yuan, Y.; Cui, L.; Wang, Z.; Yue, T. Cyclodextrin-assisted extraction of phenolic compounds: Current research and future prospects. Trends Food Sci. Technol. 2018, 79, 19-27. [CrossRef]

107. Del Valle, E.M. Cyclodextrins and their uses: A review. Process Biochem. 2004, 39, 1033-1046. [CrossRef]

108. Aksamija, A.; Polidori, A.; Plasson, R.; Dangles, O.; Tomao, V. The inclusion complex of rosmarinic acid into beta-cyclodextrin: A thermodynamic and structural analysis by NMR and capillary electrophoresis. Food Chem. 2016, 108, 258-263. [CrossRef] [PubMed]

109. Fateminasab, F.; Bordbar, A.; Shityakov, S.; Saboury, A. Molecular insights into inclusion complex formation between $\beta$ - and $\gamma$-cyclodextrins and rosmarinic acid. J. Mol. Liq. 2020, 314, e113802. [CrossRef]

110. Astray, G.; Gonzalez-Barreiro, C.; Mejuto, J.C.; Rial-Otero, R.; Simal-Gándara, J. A review on the use of cyclodextrins in foods. Food Hydrocoll. 2009, 23, 1631-1640. [CrossRef]

111. Çelik, S.E.; Özyürek, M.; Tufan, A.N.; Güçlü, K.; Apak, R. Spectroscopic study and antioxidant properties of the inclusion complexes of rosmarinic acid with natural and derivative cyclodextrins. Spectrochim. Acta A Mol. Biomol. Spectrosc. 2011, 78, 1615-1624. [CrossRef]

112. Rijo, P.; Matias, D.; Fernandes, A.S.; Simões, M.F.; Nicolai, M.; Reis, C.P. Antimicrobial plant extracts encapsulated into polymeric beads for potential application on the skin. Polymers 2014, 6, 479-490. [CrossRef] 
113. Rijo, P.; Falé, P.L.; Serralheiro, M.L.; Simões, M.F.; Gomes, A.; Reis, C. Optimization of medicinal plant extraction methods and their encapsulation through extrusion technology. Measurement 2014, 58, 249-255. [CrossRef]

114. Stojanovic, R.; Belscak-Cvitanovic, A.; Manojlovic, V.; Komes, D.; Nedovic, V.; Bugarski, B. Encapsulation of thyme (Thymus serpyllum L.) aqueous extract in calcium alginate beads. J. Sci. Food Agric. 2012, 92, 685-696. [CrossRef]

115. Ge, L.; Zhu, M.; Li, X.; Xu, Y.; Ma, X.; Shi, R.; Li, D.; Mu, C. Development of active rosmarinic acid-gelatin biodegradable films with antioxidant and long-term antibacterial activities. Food Hydrocoll. 2018, 83, 308-316. [CrossRef]

116. Gimenez-Rota, C.; Palazzo, I.; Scognamiglio, M.R.; Mainar, A.; Reverchon, E.; Della Porta, G. $\beta$-Carotene, $\alpha$-tocoferol and rosmarinic acid encapsulated within PLA/PLGA microcarriers by supercritical emulsion extraction: Encapsulation efficiency, drugs shelf-life and antioxidant activity. J. Supercrit. Fluids 2019, 146, 199-207. [CrossRef]

117. Figueroa-Lopez, K.J.; Vicente, A.A.; Reis, M.A.; Torres-Giner, S.; Lagaron, J.M. Antimicrobial and antioxidant performance of various essential oils and natural extracts and their incorporation into biowaste derived poly (3-hydroxybutyrate-co-3hydroxyvalerate) layers made from electrospun ultrathin fibers. Nanomaterials 2019, 9, 144. [CrossRef] [PubMed]

118. Baranauskaite, J.; Duman, G.; Corapcioglu, G.; Baranauskas, A.; Taralp, A.; Ivanauskas, l.; Bernatoniene, J. Liposomal Incorporation to Improve Dissolution and Stability of Rosmarinic Acid and Carvacrol Extracted from Oregano (O. onites L.). BioMed Res. Int. 2018, 2018, 6147315. [CrossRef]

119. Yucel, Ç.; Karatoprak, G.Ş.; Değim, İ.T. Anti-aging formulation of rosmarinic acid-loaded ethosomes and liposomes. J. Microencapsul. 2019, 36, 180-191. [CrossRef] [PubMed]

120. Subongkot, T.; Ngawhirunpat, T.; Opanasopit, P. Development of ultradeformable liposomes with fatty acids for enhanced dermal rosmarinic acid delivery. Pharmaceutics 2021, 13, 404. [CrossRef]

121. Borges, A.; de Freitas, V.; Mateus, N.; Fernandes, I.; Oliveira, J. Solid lipid nanoparticles as carriers of natural phenolic compounds. Antioxidants 2020, 9, 998. [CrossRef]

122. Madureira, A.R.; Campos, D.A.; Oliveira, A.; Sarmento, B.; Pintado, M.M.; Gomes, A.M. Insights into the protective role of solid lipid nanoparticles on rosmarinic acid bioactivity during exposure to simulated gastrointestinal conditions. Colloids Surf. B 2016, 139, 277-284. [CrossRef] [PubMed]

123. Fachel, F.N.S.; Schuh, R.S.; Veras, K.S.; Bassani, V.L.; Koester, L.S.; Henriques, A.T.; Braganhol, E.; Teixeira, H.F. An overview of the neuroprotective potential of rosmarinic acid and its association with nanotechnology-based delivery systems: A novel approach to treating neurodegenerative disorders. Neurochem. Int. 2019, 122, 47-58. [CrossRef] [PubMed]

124. Bhatt, R.; Singh, D.; Prakash, A.; Mishra, N. Development, characterization and nasal delivery of rosmarinic acid-loaded solid lipid nanoparticles for the effective management of Huntington's disease. Drug Deliv. 2015, 22, 931-939. [CrossRef]

125. Chaiyana, W.; Anuchapreeda, S.; Somwongin, S.; Marsup, P.; Lee, K.-H.; Lin, W.-C.; Lue, S.-C. Dermal delivery enhancement of natural anti-ageing compounds from Ocimum sanctum Linn. extract by nanostructured lipid carriers. Pharmaceutics 2020, $12,309$. [CrossRef]

126. Fachel, F.N.S.; Medeiros-Neves, B.; Dal Prá, M.; Schuh, R.S.; Veras, K.S.; Bassani, V.L.; Koester, L.S.; Henriques, A.T.; Braganhol, E.; Teixeira, H.F. Box-Behnken design optimization of mucoadhesive chitosan-coated nanoemulsions for rosmarinic acid nasal delivery-In vitro studies. Carbohyd. Polym. 2018, 199, 572-582. [CrossRef]

127. Marafon, P.; Fachel, F.N.S.; Dal Prá, M.; Bassani, V.L.; Koester, L.S.; Henriques, A.T.; Braganhol, E.; Teixeira, H.F. Development, physico-chemical characterization and in-vitro studies of hydrogels containing rosmarinic acid-loaded nanoemulsion for topical application. J. Pharm. Pharmacol. 2019, 71, 1199-1208. [CrossRef] [PubMed]

128. Torin, R.F.D.S.; Camani, P.H.; da Silva, L.N.; Sato, J.A.P.; Ferreira, F.F.; Rosa, D.D.S. Effect of clay and clay/essential oil in packaging films. Polym. Comp. 2018, 39, 4034-4040. [CrossRef]

129. Nguemtchouin, M.G.; Ngassoum, M.B.; Chalier, P.; Kamga, R.; Ngamo, L.S.; Cretin, M. Ocimum gratissimum essential oil and modified montmorillonite clay, a means of controlling insect pests in stored products. J. Stored Prod. Res. 2013, 52, 57-62. [CrossRef]

130. Joshi, G.V.; Kevadiya, B.D.; Patel, H.A.; Bajaj, H.C.; Jasra, R.V. Montmorillonite as a drug delivery system: Intercalation and in vitro release of timolol maleate. Int. J. Pharm. 2009, 374, 53-57. [CrossRef]

131. Giannakas, A.; Tsagkalias, I.; Achilias, D.S.; Ladavos, A. A novel method for the preparation of inorganic and organo-modified montmorillonite essential oil hybrids. Appl. Clay Sci. 2017, 146, 362-370. [CrossRef]

132. Kinninmonth, M.A.; Liauw, C.M.; Verran, J.; Taylor, R.; Edwards-Jones, V.; Shaw, D.; Webb, M. Investigation into the suitability of layered silicates as adsorption media for essential oils using FTIR and GC-MS. Appl. Clay Sci. 2013, 83, 415-425. [CrossRef]

133. Pinto, L.; Bonifacio, M.A.; De Giglio, E.; Santovito, E.; Cometa, S.; Bevilacqua, A.; Baruzzi, F. Biopolymer hybrid materials: Development, characterization, and food packaging applications. Food Packag. Shelf Life 2021, 28, 100676. [CrossRef]

134. Azeredo, H.M.; Otoni, C.G.; Corrêa, D.S.; Assis, O.B.; de Moura, M.R.; Mattoso, L.H.C. Nanostructured antimicrobials in food packaging-Recent advances. Biotechnol. J. 2019, 14, 1900068. [CrossRef] [PubMed]

135. Muráth, S.; Alsharif, N.B.; Sáringer, S.; Katana, B.; Somosi, Z.; Szilagyi, I. Antioxidant materials based on 2D nanostructures: A review on recent progresses. Crystals 2020, 10, 148. [CrossRef]

136. Saucedo-Zuñiga, J.N.; Sánchez-Valdes, S.; Ramírez-Vargas, E.; Guillen, L.; Ramos-deValle, L.F.; Graciano-Verdugo, A.; UribeCalderón, J.A.; Valera-Zaragoza, M.; Lozano-Ramírez, T.; Rodríguez-González, J.A.; et al. Controlled release of essential oils using laminar nanoclay and porous halloysite/essential oil composites in a multilayer film reservoir. Micropor. Mesopor. Mat. 2021, 316, 110882. [CrossRef] 
137. Golbashy, M.; Sabahi, H.; Allahdadi, I.; Nazokdast, H.; Hosseini, M. Synthesis the montmorillonite-pomegranate (Punicagranatum, L.) peel polyphenols nanostructure as a drug delivery vehicle. Biomed. Pharmacol. J. 2016, 9, 385-392. [CrossRef]

138. Efrati, R.; Natan, M.; Pelah, A.; Haberer, A.; Banin, E.; Dotan, A.; Ophir, A. The combined effect of additives and processing on the thermal stability and controlled release of essential oils in antimicrobial films. J. Appl. Polym. Sci. 2014, 131, 40564. [CrossRef]

139. Izadi, M.; Shahrabi, T.; Mohammadi, I.; Ramezanzadeh, B. Synthesis of impregnated Na+-montmorillonite as an eco-friendly inhibitive carrier and its subsequent protective effect on silane coated mild steel. Prog. Org. Coat. 2019, 135, 135-147. [CrossRef]

140. De Souza, F.S.; Spinelli, A. Caffeic acid as a green corrosion inhibitor for mild steel. Corros. Sci. 2009, 51, 642-649. [CrossRef]

141. Alibakhshi, E.; Ramezanzadeh, M.; Haddadi, S.A.; Bahlakeh, G.; Ramezanzadeh, B.; Mahdavian, M. Persian Liquorice extract as a highly efficient sustainable corrosion inhibitor for mild steel in sodium chloride solution. J. Clean. Prod. 2019, 210, 660-672. [CrossRef]

142. Ejima, H.; Richardson, J.J.; Caruso, F. Metal-phenolic networks as a versatile platform to engineer nanomaterials and biointerfaces. Nano Today 2017, 12, 136-148. [CrossRef]

143. Zhong, B.; Lin, J.; Liu, M.; Jia, Z.; Luo, Y.; Jia, D.; Liu, F. Preparation of halloysite nanotubes loaded antioxidant and its antioxidative behaviour in natural rubber. Polym. Degrad. Stab. 2017, 141, 19-25. [CrossRef]

144. Gorrasi, G. Dispersion of halloysite loaded with natural antimicrobials into pectins: Characterization and controlled release analysis. Carbohydr. Polym. 2015, 127, 47-53. [CrossRef] [PubMed]

145. Biddeci, G.; Cavallaro, G.; Di Blasi, F.; Lazzara, G.; Massaro, M.; Milioto, S.; Parisi, F.; Riela, S.; Spinelli, G. Halloysite nanotubes loaded with peppermint essential oil as filler for functional biopolymer film. Carbohydr. Polym. 2016, 152, 548-557. [CrossRef]

146. Mishra, G.; Dash, B.; Pandey, S. Layered double hydroxides: A brief review from fundamentals to application as evolving biomaterials. Appl. Clay Sci. 2018, 153, 172-186. [CrossRef]

147. Rossi, C.; Schoubben, A.; Ricci, M.; Perioli, L.; Ambrogi, V.; Latterini, L.; Aloisi, G.G.; Rossi, A. Intercalation of the radical scavenger ferulic acid in hydrotalcite-like anionic clays. Int. J. Pharm. 2005, 295, 47-55. [CrossRef]

148. Kong, X.; Jin, L.; Wei, M.; Duan, X. Antioxidant drugs intercalated into layered double hydroxide: Structure and in vitro release. Appl. Clay Sci. 2010, 49, 324-329. [CrossRef]

149. Pérez Amaro, L.; Cicogna, F.; Passaglia, E.; Morici, E.; Oberhauser, W.; Al-Malaika, S.; Dintcheva, N.T.; Coiai, S. Thermo-oxidative stabilization of poly (lactic acid) with antioxidant intercalated layered double hydroxides. Polym. Degrad. Stab. 2016, 133, 92-100. [CrossRef]

150. Bugatti, V.; Esposito, L.; Franzetti, L.; Tammaro, L.; Vittoria, V. Influence of the powder dimensions on the antimicrobial properties of modified layered double hydroxide. Appl. Clay Sci. 2013, 75, 46-51. [CrossRef]

151. Costantino, U.; Bugatti, V.; Gorrasi, G.; Montanari, F.; Nocchetti, M.; Tammaro, L.; Vittoria, V. New polymeric composites based on poly ( $\epsilon$-caprolactone) and layered double hydroxides containing antimicrobial species. ACS Appl. Mater. Interfaces 2009, 1, 668-677. [CrossRef] [PubMed]

152. Gorrasi, G.; Bugatti, V.; Vittoria, V. Pectins filled with LDH-antimicrobial molecules: Preparation, characterization and physical properties. Carbohydr. Polym. 2012, 89, 132-137. [CrossRef] [PubMed]

153. Cheng, H.M.; Gao, X.W.; Zhang, K.; Wang, X.R.; Zhou, W.; Li, S.J.; Cao, X.L.; Yan, D.P. A novel antimicrobial composite: ZnAl-hydrotalcite with p-hydroxybenzoic acid intercalation and its possible application as a food packaging material. New $J$. Chem. 2019, 43, 19408-19414. [CrossRef]

154. Sisti, L.; Totaro, G.; Bozzi Cionci, N.; Di Gioia, D.; Celli, A.; Verney, V.; Leroux, F. Olive mill wastewater valorization in multifunctional biopolymer composites for antibacterial packaging application. Int. J. Mol. Sci. 2019, 20, 2376. [CrossRef] [PubMed]

155. Sisti, L.; Totaro, G.; Celli, A.; Diouf-Lewis, A.; Verney, V.; Leroux, F. A new valorization route for Olive Mill wastewater: Improvement of durability of PP and PBS composites through multifunctional hybrid systems. J. Environ. Chem. Eng. 2019, 7, 103026. [CrossRef]

156. Coiai, S.; Cicogna, F.; Pinna, S.; Spiniello, R.; Onor, M.; Oberhauser, W.; Coltelli, M.B.; Passaglia, E. Antibacterial LDPE-based nanocomposites with salicylic and rosmarinic acid modified layered double hydroxides. Appl. Clay Sci. 2021, $214,106276$. [CrossRef]

157. Khalil, I.; Yehye, W.A.; Etxeberria, A.E.; Alhadi, A.A.; Dezfooli, S.M.; Julkapli, N.B.M.; Basirun, W.J.; Seyfoddin, A. Nanoantioxidants: Recent trends in antioxidant delivery applications. Antioxidants 2020, 9, 24. [CrossRef]

158. Arriagada, F.; Gunther, G.; Morales, J. Nanoantioxidant-based silica particles as flavonoid carrier for drug delivery applications. Pharmaceutics 2020, 12, 302. [CrossRef]

159. Liu, H.; Yu, H.; Jin, P.; Jiang, M.; Zhu, G.; Duan, Y.; Yang, Z.; Qiuc, H. Preparation of mesoporous silica materials functionalized with various amino-ligands and investigation of adsorption performances on aromatic acids. Chem. Eng. J. 2020, 379, 122405122414. [CrossRef]

160. Tabatabaeian, K.; Simayee, M.; Fallah-Shojaie, A.; Mashayekhi, F. N-doped carbon nanodots@UiO-66-NH2 as novel nanoparticles for releasing of the bioactive drug, rosmarinic acid and fluorescence imaging. DARU J. Pharm. Sci. 2019, 27, 307-315. [CrossRef]

161. Sarkar, A.; Shukla, S.P.; Adhikari, S.; Mukherjee, T. Synthesis, stabilisation and surface modification of gold and silver nanoparticles by rosmarinic acid and its analogues. Int. J. Nanotechnol. 2010, 7, 1027-1037. [CrossRef]

162. Paradossi, G.; Cavalieri, F.; Chiessi, E. A conformational study on the algal polysaccharide ulvan. Macromolecules 2002, 35, 6404-6411. [CrossRef] 
163. Morais, T.; Cotas, J.; Pacheco, D.; Pereira, L. Seaweeds compounds: An ecosustainable source of cosmetic ingredients? Cosmetics 2021, 8, 8. [CrossRef]

164. Amin, H.H. Safe ulvan silver nanoparticles composite films for active food packaging. Am. J. Biochem. Biotechnol. 2021, 17, 28-39. [CrossRef]

165. Gruskiene, R.; Kavleiskaja, T.; Staneviciene, R.; Kikionis, S.; Ioannou, E.; Serviene, E.; Roussis, V.; Sereikaite, J. Nisin-loaded ulvan particles: Preparation and characterization. Foods 2021, 10, 1007. [CrossRef] [PubMed]

166. Bang, T.H.; Van, T.T.T.; Hung, L.X.; Ly, B.M.; Nhut, N.D.; Thuy, T.T.T.; Huy, B.T. Nanogels of acetylated ulvan enhance the solubility of hydrophobic drug curcumin. Bull. Mater. Sci. 2019, 42, 1. [CrossRef]

167. Maiti, P.; Dunbar, G. Use of curcumin, a natural polyphenol for targeting molecular pathways in treating age-related neurodegenerative diseases. Int. J. Mol. Sci. 2018, 19, 1637. [CrossRef]

168. Dash, M.; Samal, S.K.; Morelli, A.; Bartoli, C.; Declercq, H.A.; Douglas, T.E.L.; Dubruel, P.; Chiellini, F. Ulvan-chitosan polyelectrolyte complexes as matrices for enzyme induced biomimetic mineralization. Carbohydr. Polym. 2018, 182, 254-264. [CrossRef]

169. Cord-Landwehr, S.; Richter, C.; Wattjes, J.; Sreekumar, S.; Singh, R.; Basa, S.; El Gueddari, N.E.; Moerschbacher, B.M. Patterns matter part 2: Chitosan oligomers with defined patterns of acetylation React. Funct. Polym. 2020, 151, 104577. [CrossRef]

170. Fernández-Díaz, C.; Coste, O.; Malta, E.-J. Polymer chitosan nanoparticles functionalized with Ulva ohnoi extracts boost in vitro ulvan immunostimulant effect in Solea senegalensis macrophages. Algal Res. 2017, 26, 135-142. [CrossRef]

171. Barros, A.A.A.; Alves, A.; Nunes, C.; Coimbra, M.A.; Pires, R.A.; Reis, R.L. Carboxymethylation of ulvan and chitosan and their use as polymeric components of bone cements. Acta Biomater. 2013, 9, 9086-9097. [CrossRef]

172. Li, N.; Liu, W.; Shen, Y.; Mei, J.; Xie, J. Coating effects of $\varepsilon$-polylysine and rosmarinic acid combined with chitosan on the storage quality of fresh half-smooth tongue sole (Cynoglossus semilaevis Günther) fillets. Coatings 2019, 9, 273. [CrossRef]

173. Osakabe, N.; Takano, H.; Sanbongi, C.; Yasuda, A.; Yanagisawa, R.; Inoue, K.; Yoshikawa, T. Anti-inflammatory and anti-allergic effect of rosmarinic acid (RA); inhibition of seasonal allergic rhinoconjunctivitis (SAR) and its mechanism. Biofactors 2004, 21, 127-131. [CrossRef] [PubMed]

174. Fachel, F.N.S.; Michels, L.R.; Hofstätter Azambuja, J.; Spies Lenz, G.; Espindola Gelsleichter, N.; Endres, M.; Nathali Scholl, J.; Silvestri Schuh, R.; Gatto Barschak, A.; Figueiró, F.; et al. Chitosan-coated rosmarinic acid nanoemulsion nasal administration protects against LPS-induced memory deficit, neuroinflammation, and oxidative stress in Wistar rats. Neurochem. Int. 2020, 141, 104875. [CrossRef] [PubMed]

175. Ferreira, J.D.L.M.; Chahud, F.; Ramalho, L.N.; Modulo, C.M.; Vieira, L.C.; Reinach, P.S.; Rodrigues, M.D.L.V.; Cunha, A.S.; Paula, J.S. Rosmarinic acid suppresses subconjunctival neovascularization in experimental glaucoma surgery. Curr. Eye Res. 2015, 40, 1134-1140. [CrossRef]

176. Vieira, L.C.; de Souza Moreira, C.P.; Moreira Castro, B.F.; Lacerda Cotta, O.A.; Silva, L.M.; de Oliveira Fulgêncio, G.; Silva-Cunha, A.; Fialho, S.L. Rosmarinic acid intravitreal implants: A new therapeutic approach for ocular neovascularization. Planta Med. 2020, 86, 1286-1297. [CrossRef]

177. Vatankhah, E.; Hamedi, S.; Ramezani, O. Surfactant-assisted incorporation of rosmarinic acid into electrosprayed poly (lacticco-glycolic acid) microparticles with potential for cosmetic and pharmaceutical applications. Polym. Test. 2020, 81, 106180. [CrossRef]

178. Azimi, B.; Thomas, L.; Fusco, A.; Kalaoglu-Altan, O.I.; Basnett, P.; Cinelli, P.; De Clerck, K.; Roy, I.; Donnarumma, G.; Coltelli, M.-B.; et al. Electrosprayed chitin nanofibril/electrospun polyhydroxyalkanoate fiber mesh as functional nonwoven for skin application. J. Funct. Biomater. 2020, 11, 62. [CrossRef]

179. Azimi, B.; Ricci, C.; Fusco, A.; Zavagna, L.; Linari, S.; Donnarumma, G.; Hadrich, A.; Cinelli, P.; Coltelli, M.-B.; Danti, S.; et al. Electrosprayed shrimp and mushroom nanochitins on cellulose tissue for skin contact application. Molecules 2021, $26,4374$. [CrossRef]

180. Morelli, A.; Betti, M.; Puppi, D.; Chiellini, F. Design, preparation and characterization of ulvan based thermosensitive hydrogels. Carbohydr Polym. 2016, 136, 1108-1117. [CrossRef]

181. Morelli, A.; Massironi, A.; Puppi, D.; Creti, D.; Domingo Martinez, E.; Bonistalli, C.; Fabroni, C.; Morgenni, F.; Chiellini, F. Development of ulvan-based emulsions containing flavour and fragrances for food and cosmetic applications. Flav. Frag. J. 2019, 34, 411-425. [CrossRef]

182. Gadenne, V.; Lebrun, L.; Jouenne, T.; Thebault, P. Antiadhesive activity of ulvan polysaccharides covalently immobilized onto titanium surface. Colloids Surf. B Biointerfaces 2013, 112, 229-236. [CrossRef] [PubMed]

183. Jeong, Y.; Yoo, J.S.; Sung, M.K. Marine fouling resistance of Ulvan-grafted solid surface. Bull. Korean Chem. Soc. 2018, 39, 1459-1462. [CrossRef]

184. Alves, A.; Pinho, E.D.; Neves, N.M.; Sousa, R.A.; Reis, R.L. Processing ulvan into 2D structures: Cross-linked ulvan membranes as new biomaterials for drug delivery applications. Int. J. Pharm. 2012, 426, 76-81. [CrossRef] [PubMed]

185. Sulastri, E.; Lesmana, R.; Sulaiman Zubair, M.; Elamin, K.M.; Wathoni, N. A comprehensive review on ulvan based hydrogel and its biomedical applications. Chem. Pharm. Bull. 2021, 69, 432-443. [CrossRef] [PubMed] 